\title{
Cell Tracking of Adult Neural Stem Cells From The Subependymal Zone In Vitro Reveals Cell Type- Specific Impacts On Cell Cycle Progression By The Extracellular Matrix Molecule Tenascin-C
}

\section{Elena Schaberg}

Ruhr-Universität Bochum: Ruhr-Universitat Bochum

\section{Magdalena Götz}

Department of Physiological Genomics, Institute of Physiology, Ludwig-Maximilians University Munich, 80336 München, Germany; Institute for Stem Cell Research, Helmholtz Zentrum München, 85764 Neuherberg, Germany

Andreas Faissner ( $\square$ andreas.faissner@ruhr-uni-bochum.de )

Ruhr-University Bochum https://orcid.org/0000-0002-2211-8259

\section{Research Article}

Keywords: Adult neural stem cells, cell cycle progression, extracellular matrix, tenascin-C, time-lapse video microscopy

Posted Date: July 15th, 2021

DOI: https://doi.org/10.21203/rs.3.rs-679173/v1

License: (c) (1) This work is licensed under a Creative Commons Attribution 4.0 International License. Read Full License 


\section{Abstract}

Adult neurogenesis has been described in two canonical regions of the adult central nervous system (CNS) of rodents, the subgranular zone (SGZ) of the hippocampus and the subependymal zone (SEZ) of the lateral ventricles. The stem cell niche of the SEZ provides a privileged environment composed of a specialized extracellular matrix (ECM) that comprises the glycoproteins tenascin-C (Tnc) and laminin-1 (LN1). In the present study, we investigated the function of these ECM glycoproteins in the adult stem cell niche. Adult neural stem cells (aNSPCs) of the SEZ were prepared from wildtype $\left(T n c^{+/+}\right)$and Tnc knockout $\left(\mathrm{TnC}^{-/}\right)$mice and analyzed using molecular and cell biological approaches. A delayed maturation of aNSPCs in $\mathrm{Tnc}^{-/}$tissue was reflected by a reduced capacity to form neurospheres in response to epidermal growth factor (EGF). In order to examine a potential influence of the ECM on cell proliferation, aNSPCs of both genotypes were studied by cell tracking using digital video microscopy. aNSPCs were cultivated on three different substrates, namely poly-D-Lysine (PDL) and PDL replenished with either LN1 or Tnc for up to six days in vitro. On each of the three substrates aNSPCs displayed lineage trees that could be investigated with regard to cell cycle length. The latter appeared reduced in Tnc $^{-/}$aNSPCs on PDL and LN1 substrates, less so on Tnc that seemed to compensate the absence of the ECM compound to some extent. Close inspection of the lineage trees revealed a subpopulation of late dividing aNSPC $s_{\text {late }}$ that engaged into cycling after a notable delay. aNSPC $s_{\text {late }}$ exhibited a clearly different morphology, with a larger cell body and conspicuous processes. aNSPCs $s_{\text {late }}$ reiterated the reduction in cell cycle length on all substrates tested, which was not rescued on Tnc substrates. When the migratory activity of aNSPC-derived progeny was determined, $\mathrm{TnC}^{-/}$neuroblasts displayed significantly longer migration tracks. This was traced to an increased rate of migration episodes compared to the wildtype cells that rested for longer time periods. We conclude that Tnc intervenes in the proliferation of aNSPCs and modulates the motility of neuroblasts in the niche of the SEZ.

\section{Introduction}

The adult mammalian brain retains neural stem cells in closely defined areas, the so-called stem cell niches at the lateral ventricle and the subgranular zone of the dentate gyrus [1, 2]. The stem cells from the subependymal zone (SEZ) of the lateral ventricle are surrounded by niche astrocytes, blood vessels and their own generated progeny underneath a dense layer of ependymal cells facing the lumen of the ventricle [3-5]. These stem cells have astroglial characteristics and are also called SVZ astrocytes or type $B$ cells $[6,7,5]$. They give rise to type $C$ cells, which are fast-cycling transient amplifying progenitors (TAPs) and in the end produce type A cells which are neuroblasts generated by a final symmetric division $[8,9]$. These newborn neurons are integrated into the neuronal network of the olfactory bulb, which they reach by migration through the rostral migratory stream [10].

At the beginning, adult neural stem cells (aNSPCs) were investigated in vitro in neurosphere cultures [11] or in adherent cultures by addition of growth factors or astroglial feeder layers [12, 13]. Subsequent studies could show that the addition of such factors considerably influences the proliferation mode of 
aNSPCs $[14,9]$. On these bases, protocols were developed that allow to study the behavior of aNSPCs from the SEZ in absence of mitogenic or cell fate-changing factors [8]. This approach unraveled the intrinsic program of lineage progression and opened that possibility to investigate extracellular matrix (ECM) effects by presenting defined niche molecules in vitro $[9,8]$.

The ECM has been shown to be of great importance for the behavior of diverse cell types from different tissues [15-17]. The glycoprotein tenascin-C (Tnc) is part of the ECM in stem cell niches of the central nervous system in development and adulthood [18-23]. The close association of Tnc with stem cell environments prompted the analysis of Tnc impact on stem cell behavior during development [24-26]. The use of Tnc-knockout cells [26] as well as the cultivation on purified Tnc substrates [27] or the Tncderived peptide VSWRAPTA [28] could confirm the hypothesis that Tnc does strongly influence processes such as cell cycle progression, differentiation and neurite growth in specific contexts of early development.

Another important member of the ECM are laminins as part of the basal lamina. They are expressed in the subventricular zone of adult mice [29] and a promoting influence of laminins on cell behavior has already been reported for myoblasts [30] or neural progenitor cells [31,32] in terms of proliferation and neurogenesis. We present here a study that investigates the influence of the two extracellular matrix compounds Tnc and laminin-1 on the lineage progression of aNSPCs from the SEZ by time-lapse video microscopy and cell tracking to obtain deeper insights into the direct influence of the niche environment on adult stem cell behavior under specifically defined conditions.

\section{Material And Methods}

\section{Legal issues and animal housing}

The present study was carried out in accordance with the European Council Directive of September 22, $2010(2010 / 63 / \mathrm{EU})$ for care of laboratory animals and approved by the animal care committee of North Rhine-Westphalia, Germany, based at the LANUV (Landesamt für Umweltschutz, Naturschutz und Verbraucherschutz, Nordrhein-Westphalen, D-45659 Recklinghausen, Germany). The study was supervised by the animal welfare commissioner of Ruhr-University. All efforts were made to reduce the number of animals in the experiments. Embryos of both sexes were used. Data of this publication are based on experiments performed with Mus musculus with tenascin-C deficiency. The systemic knockout has initially been generated and published by Forsberg and colleagues [33]. The $\mathrm{Tnc}^{-/-}$knockout line was compared to wildtypes from the 129sv mouse strain that shares the same genetic background. Handling of the animals was conducted according to German animal protection laws and Federation for Laboratory Animal Science Associations (FELASA) standards. Mice were kept under controlled conditions with a 12-hour light/dark cycle and had access to water and food ad libitum. Adult animals at the age of 9- to 11-weeks were anesthetized with Isofluran (3\% (v/v), CP-Pharma) and sacrificed by cervical dislocation. The genotypes were confirmed with PCR using genomic DNA from tail biopsies with the 
following primers (forward: CTGCCAGGCATCTTTCTAGC; reverse: TTCTGCAGGTTGGAGGCAAC; neo reverse: CTGCTCTTTACTGAAGGCTC).

\section{Isolation and culture of adult neural stem cells from the murine subependymal zone}

The following isolation protocol was adapted from a published procedure [8]. 9- to 11-week old mice were sacrificed as described above. After decapitation, the brain was dissected and transferred into a $10 \mathrm{~cm}$ petri dish filled with ice-cold HBSS (\#24020-091 Gibco, Darmstadt, DE) with 10 mM HEPES (\#H0887-100 Sigma, Steinheim, DE), pH 7.4. The brain was split into its two hemispheres and cut coronally behind the optic chiasm with a surgical blade. Uncovering the ventricle from the caudal side using forceps, the lateral wall of the ventricle becomes visible. Ventricular wall tissue was dissected carefully and as thin a sheet as possible to avoid contamination with striatal tissue or myelin from the corpus callosum. The tissue was placed into a $15 \mathrm{ml}$ tube containing $10 \mathrm{ml}$ of fresh dissection medium (see above) until all brains were dissected. Afterwards, the medium was replaced by $5 \mathrm{ml}$ of dissociation medium (HBSS with 15 mM HEPES and 0.54\% (w/v) D-(+)-glucose (\#D1349 AppliChem, Darmstadt, DE) supplemented with $6.7 \mathrm{mg}$ trypsin (\#T9201-100 Sigma) and 3.3 mg hyaluronidase (\#H3884-50 Sigma) and incubated for 15 min at $37^{\circ} \mathrm{C}$. The tissue was gently triturated with a $5 \mathrm{ml}$ pipette up to 10 times and then incubated for another $15 \mathrm{~min}$ at $37^{\circ} \mathrm{C}$. Tissue dissociation was stopped by adding the same volume of EBSS (\#24010043 Gibco) with $20 \mathrm{mM} \mathrm{HEPES}$ and 4\% (w/v) BSA (\#A9418 Sigma). The cell suspension was mixed gently before it was passed through a $70 \mu \mathrm{m}$ cell strainer (\#2350 Falcon). Cells were centrifuged at $200 \mathrm{~g}$ for $5 \mathrm{~min}$. After aspirating the supernatant with a Pasteur pipette, cells were re-suspended in $10 \mathrm{ml}$ of icecold HBSS with $0.9 \mathrm{M}$ saccharose (\#S/8600/60 Fisher Chemicals). Cells were centrifuged again for 15 min at $450 \mathrm{~g}$. The resulting cell pellet was re-suspended in $2 \mathrm{ml}$ ice-cold EBSS with $20 \mathrm{mM}$ HEPES and $4 \%$ $(\mathrm{w} / \mathrm{v})$ BSA. $5 \mathrm{ml}$ of the same solution were filled into a fresh $15 \mathrm{ml}$ tube. The $2 \mathrm{ml}$ cell suspension was gently applied to the top of the fresh solution. A final centrifugation step at $250 \mathrm{~g}$ for 9 min was carried out, followed by re-suspension of the pellet in culture medium containing DMEM/F12 (\#11320-074 Gibco) with 1x B27 (\#17504-044 Gibco), 1x penicillin/streptomycin (\#P4333 Sigma) and 8 mM HEPES. The yield of one entire brain was seeded onto a poly-D-lysine $(20 \mu \mathrm{g} / \mathrm{ml}$, \#P0899 Sigma) coated well of a 24-well culture plate. As optional treatment, 24-well culture plates were coated further with $10 \mu \mathrm{g} / \mathrm{ml}$ Laminin-1 (LN1) (\#354259 Corning) or $25 \mu \mathrm{g} / \mathrm{ml}$ Tenascin-C (non-commercial, self-produced as described [34]). The cells were incubated at $37^{\circ} \mathrm{C}$ and $5 \%(\mathrm{v} / \mathrm{v}) \mathrm{CO} 2$.

\section{Time-lapse video microscopy}

For the detailed investigation of adult neural stem cell proliferation behavior, the 24-well plate was placed into the closed system of an Axiovert 200M equipped with an AxioCam HRm and AxioVision-4.8.1 software (all from Carl Zeiss, Oberkochen, DE). Additionally, the two controlling elements 'Tempcontrol 37 - 2 digital' and 'CTI-Controller 3700 digital' (PeCon GmbH, Erbach, DE) were used for stable temperature and $\mathrm{pH}$ conditions, respectively. Conditions were adjusted $1 \mathrm{~h}$ before use. Over a period of 6 days, 8 visual fields per well were documented every 5 min with defined XYZ-coordinates controlled by a moving stage (Märzhäuser, Wetzlar, DE) to ensure a sharp focus over the whole period of time. Thereby, a stack from 
about 1680 single images can be combined to obtain a time-lapse video with detailed information about the cell behavior in vitro.

\section{Cell lineage tracking}

To follow the lineage of a single mother cell, the obtained stack from time-lapse video microscopy was loaded into Fiji software. First, the visual field was scanned for proliferation events. When there was a proliferative cell, it was tracked from the beginning and each time point of cell division was noted with respect to the direct precursor. With this information, a lineage tree could be drawn that gave precise evidence for the cell cycle length of each generation. Each bifurcation in this tree means a divisional event and the length of the vertical lines corresponds to the duration of the observed cell cycle. Thus, each mother cell establishes its own individual lineage tree. Every dividing cell from five biologically independent experiments was included into the analysis $(N=5$; wildtype $n=497$ and knockout $n=350)$.

\section{Migration analysis}

Another read-out of the time-lapse videos focused on the migratory behavior of the generated neuroblasts. In most cases, neuroblasts arose from the final division of a mother cell in this culture system, which could be identified by a bipolar morphology and the gain of migratory properties. With Fiji software, cell movement could be evaluated by using the 'Manual Tracking' Plugin. Parameters like distance (in arbitrary units, AU) and migration time (in min) were directly analyzed, while the speed parameter was calculated as distance per time (in AU/min).

\section{Neurosphere assay}

To calculate the number of stem cells within the wildtype and knockout SVZ, tissue was dissected and digested as described above and then seeded into T25 flasks with a density of $750 \mathrm{cells} / \mathrm{ml}$ in DMEM/F12 medium supplemented with B27, penicillin/streptomycin, 8 mM HEPES and epidermal growth factor (20 ng/ml, \#100 - 15 PeproTech, Hamburg, DE). Without a coated surface, the stem cells grow in suspension and build neurospheres upon proliferation. After cells were incubated at $37^{\circ} \mathrm{C}$ and $5 \%(\mathrm{v} / \mathrm{v})$ $\mathrm{CO} 2$ and allowed to grow for 7 days, they were fixed by the addition of $1 \%(\mathrm{w} / \mathrm{v})$ PFA into the culture medium. The total number of spheres per flask was counted under an inverted cell culture microscope with the help of a grid. As the cells were seeded in clonal density, one sphere was expected to originate from one stem cell and should not result from fusion events due to agitation of the cultivation medium. Thereby, this method was used as an in vitro approach to determine stem cell numbers in both genotypes.

\section{mRNA expression analysis via RT-PCR}

To isolate mRNA from the tissue, three pieces of lateral ventricular wall tissue were pooled for one sample and covered with $250 \mu \mathrm{l}$ lysis buffer supplemented with $2.5 \mu \mathrm{l}$ ß-mercaptoethanol from the GenEluteTM Mammalian Total RNA Miniprep Kit according to manufacturer's instructions (\#RTN350 Sigma). An oncolumn DNAse digestion step was inserted (\#DNASE70 Sigma). After elution with $30 \mu \mathrm{l}$ 2O, RNA 
concentrations were measured with a photometer (Hellma Analytics). Purified mRNA was used for cDNA synthesis. If possible, $0.5 \mu \mathrm{g}$ RNA was taken for one reaction. When concentrations were minute, the whole yield of mRNA was used into the synthesis reaction. Manufacturer's instructions for the First Strand cDNA Synthesis Kit were followed (\#K1612 Thermo Scientific). The RT-PCR method was used to analyze changes in gene expression levels between the wildtype and Tnc knockout mice. The regulation was estimated in a semi-quantitative manner by setting amplicon levels in relation to a housekeeping gene that does not underlie regulation in the corresponding tissue. ß-actin was generally used as reference gene. For detailed information concerning the used primers please see the supplementary material section (supplemental table S3).

\section{Protein expression analysis via Western blot}

For protein analysis, tissue was lysed with $100 \mu$ l of protein lysis buffer $(50 \mathrm{mM}$ Tris/ $\mathrm{HCl} \mathrm{pH} \mathrm{7.4,} 150 \mathrm{mM}$ $\mathrm{NaCl}, 5 \mathrm{mM}$ EDTA, 5 mM EGTA, 1\% (v/v) Triton-X 100, 0.1\% (v/v) Na-deoxycholate, 0.1\% (v/v) SDS, 1 mM orthovanadate, $40 \mathrm{mM}$ sodium fluoride) supplemented with $10 \mu \mathrm{l} / \mathrm{ml}$ PMSF (\#195381 MP Biomedicals) and $10 \mu \mathrm{l} / \mathrm{ml}$ Aprotinin (\#10 981532001 Roche) as protease inhibitors. After mechanical trituration of the tissue, samples were incubated for $15 \mathrm{~min}$ on ice followed by centrifugation at $16.000 \mathrm{rpm}$ for $15 \mathrm{~min}$ at $4^{\circ} \mathrm{C}$. The supernatant was transferred to a new tube and concentrations were determined with PierceTM BCA Protein Assay Kit (\#23225 Thermo Scientific). A protein amount of $10 \mu \mathrm{g}$ was loaded onto a $10 \%(\mathrm{v} / \mathrm{v})$ polyacrylamide gel. Gels ran with a current of $15 \mathrm{~mA}$ for $1 \mathrm{~h}$. Proteins were transferred to a PVDF membrane by applying a current of $75 \mathrm{~mA}$ for $1 \mathrm{~h}$. Membranes were blocked with $5 \%(\mathrm{w} / \mathrm{v})$ milk powder (Heirler, Radolfzell, DE) in TBS buffer $(10 \mathrm{mM}$ Tris/HCl pH 7.4 with $150 \mathrm{mM} \mathrm{NaCl})$ for $2 \mathrm{~h}$, before primary antibodies were diluted in blocking buffer and incubated overnight at $4^{\circ} \mathrm{C}$. After three cycles of washing with TBST (TBS with 0.05\% Tween-20 (VWR Chemicals, Darmstadt, DE)), membranes were covered with secondary antibodies diluted in blocking buffer for $1 \mathrm{~h}$ and rotated on an orbital shaker. Before the blot was developed, membranes were washed again for three times with TBST and once with TBS to remove Tween residues. Afterwards, both solutions of the Clarity Western ECL Substrate (\#1705061 BioRad) were mixed in equal parts and applied onto the membrane to incubate for $5 \mathrm{~min}$. The solution was drained from the membrane to document chemiluminescent signals using the MicroChemi (DNR Bio-Imaging systems).

\section{Differentiation assay and immunocytochemistry}

To reveal differences in the cell fate of adult neural stem cells driven by the different extracellular matrix components which they were exposed to, cells were incubated for 7 days at $37^{\circ} \mathrm{C}$ and $5 \%(\mathrm{v} / \mathrm{v}) \mathrm{CO} 2$. Within this time period, the progeny generated by stem cells in the culture was able to differentiate to neuroblasts (Dcx+), astrocytes (GFAP+) or oligodendrocytes (04+). To stain the culture after 7 div, cells were fixed with $4 \%(\mathrm{w} / \mathrm{v})$ PFA for $10 \mathrm{~min}$. After three washing steps with PBS for $5 \mathrm{~min}$, cells were incubated with the primary antibodies at $4^{\circ} \mathrm{C}$ over night (mouse IgM anti-04 (RRID: AB_94872; 1:30), rabbit anti-GFAP (RRID: AB_477010; 1:300) and mouse anti-blll-tubulin (RRID: AB_477590; 1:300)) and 0.5\% (v/v) Triton X-100 (\#A4975 AppliChem). After three washing steps with PBS for 15 min each, 
secondary antibodies were diluted in the same buffer as primary antibodies and incubated for $1 \mathrm{~h}$ at room temperature (goat anti-mouse IgM AF488 (RRID: AB_2338849), goat anti-mouse IgG Cy3 (RRID: AB_2338686) and goat anti-rabbit IgG Cy5 (RRID: AB_2338013), all 1:300 from Dianova; supplemental table S4). Coverslips were placed in a drop of ImmuMount on an object slide with the cells facing downwards. Stainings were documented at an Axiophot (Zeiss).

\section{Tissue fixation and preparation of cryosections}

For immunohistochemical stainings, the brain was taken out of the skull and directly stored in $4 \%(\mathrm{w} / \mathrm{v})$ PFA at $4^{\circ} \mathrm{C}$ for $48 \mathrm{~h}$. This fixation was followed by a sucrose gradient: brains stayed at $10 \%(\mathrm{w} / \mathrm{v})$ sucrose for 6 hours, $20 \%(w / v)$ sucrose for 24 hours and 30\% (w/v) sucrose for another 24 hours, before they were embedded in tissue freezing medium (Leica Microsystems, Wetzlar, DE) and placed onto dry ice to ensure fast freezing of the tissue. Cryosections were cut at the Leica Cryostat CM3050S with $14 \mu \mathrm{m}$ thickness .

\section{Immunohistochemistry}

Sections were thawed and allowed to dry. The tissue was encircled with a hydrophobic barrier marker (ROTI ${ }^{\circledR}$ Liquid Barrier marker, Carl Roth, Karlsruhe, DE). Sections were rehydrated in PBS with $1.7 \%(\mathrm{w} / \mathrm{v})$ $\mathrm{NaCl}$ (Fisher Chemical) for one hour. Afterwards, sections were covered for $2 \mathrm{~h}$ with blocking buffer containing 10\% (v/v) normal goat serum (Dianova), 1\% (w/v) BSA (Sigma) and 0.1\% (v/v) triton X-100 (AppliChem) in PBS. Primary antibodies were diluted in blocking buffer and incubated overnight at $4^{\circ} \mathrm{C}$. After three washing steps with PBS for 15 min each, secondary antibodies were diluted in blocking buffer and applied to the sections for $2 \mathrm{~h}$ at room temperature. Another three cycles of washing with PBS were conducted before the sections were covered with ImmuMount (Thermo Scientific) and a $24 \times 50 \mathrm{~mm}$ coverslip. Stainings were documented at the AxioZoom V16 (Carl Zeiss).

\section{Statistical analysis}

Results in bar charts are depicted as mean \pm s.e.m., unless otherwise specified. Results that are presented as Box-Whisker-Plots show the median as line, the upper and lower quartile as box and the 5-95\% percentile as whiskers. The statistical test and the number of performed experiments are indicated in the figure legends, where biological replicates are referred to as " $\mathrm{N}$ " and technical replicates are referred to as " $n$ ". The Kolmogorov-Smirnov test was used to verify Gaussian distribution. Statistical tests were done with the GraphPad Prism 7 software (Graphpad Software, San Diego, CA). Significances were graphically illustrated by * for $p<0.05$, ** for $p<0.01$ and $* \star *$ for $p<0.001$.

\section{Results}

\section{Expression pattern of Thc in the adult murine brain}

In the course of murine development, Tnc expression reaches a maximum right before birth to be strongly reduced afterwards [18]. Nevertheless, an immunohistochemical staining of frontal sections from wildtype mice at the age of 10 weeks (Fig. 1A) with polyclonal anti-Tnc revealed a restricted but distinct 
expression of Tnc around the lateral and the third ventricle (Fig. 1B). The specificity of the antibody was confirmed by controls with Tnc-deficient brain sections where staining was completely absent (Fig. 1B'). The close association of the secreted Tnc protein with stem cell niches in embryos that is maintained in the adult stage led to the assumption that this ECM component provides a beneficial environment for stem cell maintenance $[35,25]$.

\section{Tnc-deficient aNSPCs display a reduced response to EGF in vitro}

In order to probe the asserted functional role, a classical experimental approach was used to determine differences in aNSPC numbers between wildtype and Tnc-deficient mice in vitro. The clonal density assay was performed with single cells isolated from the lateral ventricular wall that were cultivated in suspension cultures in presence of the cytokine epidermal growth factor (EGF). After 7 days in vitro, the number of generated neurospheres was evaluated relatively to the sum of plated cells. Cells were seeded in clonal density to ensure that each neurosphere results from the progeny of a single stem cell. Tncdeficient cells produced significantly less neurospheres after 7 days than wildtype cells $(15.35 \% \pm 1.2 \%$ neurosphere-forming cells in wildtype cultures compared to $9.32 \% \pm 1.2 \%$ in knockout cultures, $N=5, p=$ 0.007 in unpaired students t-test, Fig. 1C).

The reduced capacity to form neurospheres could result from changes of EGF receptor (EGFR) expression. Therefore, the EGFR level in SEZ tissue in vivo was analyzed using PCR and Western blot. The expression of EGFR on mRNA level normalized to b-actin showed a decrease in Tnc-deficient animals (1.06 \pm 0.39 compared to $1.60 \pm 0.46$ in wildtypes, mean \pm s.e.m., $N=4$, Fig. 1D). The protein expression paralleled this result, as Tnc-deficient tissue seemingly displayed reduced EGFR levels compared to the control $(0.67 \pm 0.20$ in knockout SEZ $(N=3)$ compared to $1.13 \pm 0.13$ in wildtype SEZ $(N=5)$; however, not significant, $p=0.14$ in Mann-Whitney U-test, Fig. 1E). In conclusion, the aNSPC population of the SEZ of Tnc-knockout mice exhibited a tampered proliferative capacity in response to EGF. The role of the EGFR in this context remains to be established.

\section{Cell lineage tracking of adult NSPCs by time-lapse video microscopy permits measurement of cell cycle length}

A detailed evaluation of cell cycle duration in wildtype and Tnc-deficient aNSPCs was conducted with the help of time-lapse imaging over a period of 6 div. The single cells were plated onto PDL coated control dishes or to substrates additionally replenished with laminin-1 (LN1) or tenascin-C (Tnc). Each aNSPC mother cell constructed its own individual pedigree depending on the number of divisions and the length of the cell cycle (exemplary lineage trees for each condition are mapped in Fig. 2G-L). A striking attribute of lineage trees generated by aNSPCs was their synchronized sequence (Supplemental movies 1-4). Daughter cells mostly divided again after comparable cycle lengths. Note that the mapped lineage trees all showed three rounds of division. This happened in $10 \%$ of the mother cells (data not shown), but served better for illustration of the proliferation dynamics. Most of the generated trees were slenderer and displayed fewer branching points. This mapping provided a good overview of the sequential divisions of a single mother cell, but it did not yield sufficient information that permitted precise quantification and 
statistical evaluation. For this reason, the complete data set relating to cell cycle lengths was assembled in box-whisker-plots.

\section{Tracking of adult NSPCs by time-lapse video microscopy reveals differences between Tnc and LN1 substrates}

Previous studies using this tracking approach already revealed significant differences in the cell cycle lengths of subsequent generations of embryonic spinal cord NSPCs [26, 8]. Therefore, each generation was considered separately. The first generation represented a peculiar condition due to the fact that the beginning of the cycle could not be determined with precision as it laid outside of the observed time frame. This accounted for a broader distribution of the data points and no significant differences were hence observed for the first generation of wildtype aNSPCs between PDL (median of 9.7h, $n=171, N=5$ ), LN1 (9.5h, $n=185, N=5)$ and Tnc (10.8h, $n=141, N=5$; Fig. 3A) conditions. Knockout cells showed medians of 11.3h, 12.2h and 10.9h on PDL $(n=150, N=5)$, LN1 $(n=107, N=5)$ and Tnc $(n=93, N=5$, Fig. $3 A)$, respectively. In the second generation, a significant decrease of the cycle length from $21.8 \mathrm{~h}(n=157$, $N=5)$ in the control to $19.3 \mathrm{~h}$ on Tnc $(n=145, N=5, p=0.002$, Fig. 3B) was found in wildtype cells. Cell cycle length on the LN1 coating was unaltered, with 21.0h $(n=176, N=5)$. No changes were detected between the three conditions in the second generation of knockout aNSPCs (PDL: 18.7h, $n=117, N=5$; LN1: 18.1h, $n=106, N=5$; Tnc: 17.6h, $n=103, N=5$; Fig. 3B). An analogous outcome occurred in the third generation of wildtype aNSPCs (PDL: $17.2 \mathrm{~h}, \mathrm{n}=81, \mathrm{~N}=5$; LN1: 16.8h, $\mathrm{n}=125, \mathrm{~N}=5$; Tnc: $16.6 \mathrm{~h}, \mathrm{n}=67, \mathrm{~N}$ = 5) and Tnc-knockout cells (PDL: 17.0h, $n=106, N=5 ;$ LN1: 16.3h, $n=79, N=5$; Tnc: $16.1 \mathrm{~h}, \mathrm{n}=96, \mathrm{~N}=5$; Fig. 3C).

The fourth tracked generation, however, revealed a significantly shorter cell cycle in wildtype aNSPCs on the LN1 substrate (17.0h, $n=57, N=5$; Fig. 3D) compared to the control $(25.3 h, n=21, N=5, p=0.004)$. The median cell cycle on the Tnc substrate was similarly reduced to $16.3 \mathrm{~h}$, but this result did not achieve statistical significance due to a small sample size $(n=7, N=5)$. The accelerated division cycle consequent to a reduced cycle length in the presence of ECM constituents also emerged in knockout aNSPCs, where it proved significant for both substrate conditions. On LN1 aNSPCs displayed a median of 15.0h $(n=29, N=5, p=0.005$, Fig. 3D) and on Tnc a median of 15.8h $(n=52, N=5, p=0.040)$, compared to $18.3 \mathrm{~h}$ in the PDL control $(n=54, N=5)$. In conclusion, the exposure to ECM substrates like LN1 or Tnc caused an acceleration of the cell cycle of aNSPC in vitro (Supplemental table 1).

\section{Cell lineage tracking of adult NSPCs by time-lapse video microscopy reveals faster cell cycling in Tnc- knockout cultures}

So far, the study was focused on the effect of supplemented ECM-glycoproteins presented as substrates in culture. It is also of interest to consider the behavior of wildtype and knockout aNSPCs under identical culture conditions to evaluate the relative contribution of Tnc genes. Because of the impossibility to fix the time point of the first division mentioned previously, no significant changes could be traced in the first generation (Fig. 3A). In the second generation, Tnc-deficient aNSPCs cycled significantly faster on PDL (18.7h, $n=117, N=5$, Fig. 3B) compared to wildtype aNSPCs (21.8h, $n=157, N=5, p<0.001)$. An 
analogous phenomenon was also seen on LN1 (wildtype: 18.1h, $n=106, N=5$; knockout: 21.0h, $n=176$, $\mathrm{N}=5, \mathrm{p}=0.003$ ). The result on the Tnc substrate was not significant in the second generation (wildtype: 19.3h, $n=145, N=5$; knockout: $17.6 \mathrm{~h}, \mathrm{n}=103, \mathrm{~N}=5, \mathrm{p}=0.11$; Fig. 3B). In the third generation, cell cycle lengths did not show significant alterations on PDL (wildtype: 17.2h, $\mathrm{n}=81 ; \mathrm{N}=5$; knockout: 17.0h, $\mathrm{n}=$ 106, $N=5$ ) and Tnc (wildtype: 16.6h, $n=67 ; N=5$; knockout: 16.1h, $n=96 ; N=5, p=0.15 ;$ Fig. 3C). On LN1, the decrease in cell cycle length of Tnc-knockout cells was significant (16.3h, $n=79 ; N=5 ;$ Fig. $3 C$ ) compared to the wildtype $(16.8 \mathrm{~h}, \mathrm{n}=125, \mathrm{~N}=5, \mathrm{p}=0.041)$. The situation in the fourth generation was comparable in that Tnc-deficient aNSPCs $(18.3 \mathrm{~h}, \mathrm{n}=54, \mathrm{~N}=5)$ divided faster than the wildtype on PDL (25.3h, $n=21, N=5, p=0.007$; Fig. 3D). The outcome was comparable on the LN1 substrate (knockout: 15.0h, $n=29, N=5$; wildtype: 17.0h, $n=57, N=5, p<0.001$; Fig. 3D). On the Tnc coating, however, the difference was not significant (knockout: 15.8h, $n=52, N=5$; wildtype: $16.3 \mathrm{~h}, \mathrm{n}=7, \mathrm{~N}=5, \mathrm{p}=0.12$; supplemental table S1). Taken together, both the addition of Tnc as culture substrate and, alternatively, its depletion by genetic recombination in the knockout resulted in alterations of the cell cycle length in aNSPCs. Based on these results we proposed the hypothesis that the Tnc concentration is subtly balanced in the niche. Consequently, its dysregulation unsettled the proliferation behavior of aNSPCs in vitro.

\section{Identification of a subpopulation of slowly dividing aNSPCs using time-lapse video microscopy}

When the proliferation activity of aNSPCs was examined in more detail, a subset of proliferating cells appeared to engage remarkably late into cell division during the observation period of 6 days. This subset remained notably inert while the majority of proliferating cells performed two rounds of mitosis. This resulted in a remarkable extension of the temporal delay until the first round of mitosis that was clearly visible when the temporal sequences until the first division were plotted for the individual cells monitored in the cell tracking experiment (Fig. 4A). Whereas the majority of proliferating cells started their first division within the first $24 \mathrm{~h}$ of tracking, a minority stalled for up to $48 \mathrm{~h}$. In order to distinguish this subpopulation, a threshold was set at $50 \mathrm{~h}$, following the assumption that a subclass of slowly dividing aNSPCs would cluster above this hypothetical barrier. This procedure was supported by the observation that early dividing aNSPCs exhibited a different morphology compared to late dividing ones (Fig. 4B). The rapidly dividing cells were characterized by a rounded small cell body, while the late dividers presented several elongated processes emanating from a cell body that was nearly twice as large (top). An exemplary scheme of both cell morphologies was added to the phase contrast images. The durations of the first completed cell cycle were compared for the rapidly dividing as compared to the late-dividing population. On PDL, the groups differed significantly as early dividing cells needed $21.8 \mathrm{~h}$ (median, $\mathrm{n}=$ $157, N=5$; Fig. 4D) while the late subtype displayed a faster division ( $16.8 h, n=10, N=5, p=0.009)$. On $\mathrm{LN} 1$, the difference was comparable (early dividing: $21.0 \mathrm{~h}, \mathrm{n}=176, \mathrm{~N}=5$; late dividing: $17.5 \mathrm{~h}, \mathrm{n}=24, \mathrm{~N}=$ $5, p=0.03$; Fig. 4E).

In this context culturing on Tnc substrates proved an exception, because both early and late dividing cells displayed comparable cycling times (early dividing: $19.3 \mathrm{~h}, \mathrm{n}=145, \mathrm{~N}=5$; late dividing: $19.2 \mathrm{~h}, \mathrm{n}=27, \mathrm{~N}=$ 5; Fig. 4F; supplemental table S2). The proportion of early to late dividing cells was 102.2 versus 8.2 cells 
per video (mean, $\mathrm{N}=5$ ) for wildtype cultures and 81.6 versus 5.8 cells per video for knockout cultures (Fig. 4C). We propose that the late dividing aNSPCs correspond to the slow-dividing astro/radial glia that has been described previously [9]. This cell type is placed at the top of a lineage tree and generates complex pedigrees. Most of these trees are characterized by the occurrence of asymmetric cell divisions and give rise to neuronal as well as astroglial progeny. In this sense they have been perceived as genuine aNSPCs, different from already fate-restricted progenitors [8]. Because we studied this subpopulation in more detail, it will heretofore be referred to as aNSPCs $s_{\text {late. }}$.

\section{Examination of cell cycle lengths from the late-dividing subpopulation of aNSPCs}

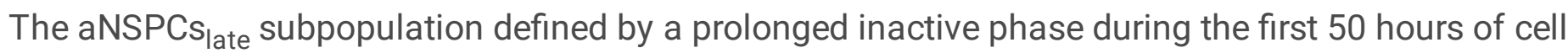
tracking was analyzed separately in more detail with regard to the behavior on different substrates (Fig. 5). To this end, the median values of time sequences of division in the different generations monitored were compared. In the second generation only minor differences on LN1 and Tnc were visible for wildtype (median on PDL: 16.8h, $\mathrm{n}=10, \mathrm{~N}=5$; LN1: 17.5h, $\mathrm{n}=24, \mathrm{~N}=5$; Tnc: 19.2h, $\mathrm{n}=27, \mathrm{~N}=5$; Fig. 5A) and Tnc ${ }^{-/-}$ aNSPCs $_{\text {late }}$ cells (median on PDL: $13.9 \mathrm{~h}, \mathrm{n}=20, \mathrm{~N}=5$; LN1: 14.0h, $\mathrm{n}=14, \mathrm{~N}=5$; Tnc: $15.2 \mathrm{~h}, \mathrm{n}=16, \mathrm{~N}=5$; Fig. $5 \mathrm{~A}$ ). In the third generation, however, the cell cycle length of wildtype aNSPC $s_{\text {late }}$ was significantly extended on Tnc compared to LN1 (18.8h, $n=24, N=5$; versus $16.5 h, n=32, N=5$, respectively, $p=0.046$; Fig. $5 B)$, while the a median of $17.2 \mathrm{~h}$ was noted on PDL $(n=9, N=5)$. Interestingly, no apparent differences were measured for $\mathrm{Tnc}^{-/-}$aNSPCs ${ }_{\text {late }}$ in the third generation (PDL: $15.9 \mathrm{~h} \mathrm{n}=37, \mathrm{~N}=5$; LN1: $15.3 \mathrm{~h}, \mathrm{n}=26, \mathrm{~N}=5$; Tnc: $14.7 \mathrm{~h}, \mathrm{n}=23, \mathrm{~N}=5$ ). In the fourth generation, the observed difference with wildtype aNSPCs $s_{\text {late }}$ was reiterated in that the cycle length was stretched to $23.3 \mathrm{~h}(n=4, N=5)$ on Tnc compared to $16.3 \mathrm{~h}(\mathrm{n}=22, N=5)$ on LN1 ( $p=0.001$, Fig. $5 \mathrm{C})$. In obvious contrast, cell cycle lengths of $\mathrm{TnC}^{-/-}$aNSPCs $_{\text {late }}$ remained largely unchanged in the fourth generation (PDL: $16.0 \mathrm{~h}, \mathrm{n}=36, \mathrm{~N}=5$; LN1: $15.7 \mathrm{~h}, \mathrm{n}=18, \mathrm{~N}=5$; Tnc: $16.0 \mathrm{~h}, \mathrm{n}=22, \mathrm{~N}=5$, Fig. $5 \mathrm{C}$ ). It is of interest to point out that the overall aNSPC population responded with an acceleration of proliferation on Tnc, whereas solely the aNSPC late subclass displayed a contrary behavior, namely protraction of the cell cycle. This provides further support for the argument that these represent two biologically different populations.

Remarkably, the prolongation of the cell cycle on Tnc was not seen with knockout aNSPCs $s_{\text {late, }}$ which may indicate that these cells have lost sensitivity to the ECM component. The asserted differences between wildtype and $\mathrm{TnC}^{-/-}{ }^{-} \mathrm{ANSPCs}_{\text {late }}$ were followed further by direct comparison of the respective cell cycle lengths under the different conditions tested. Thus, in the second generation the knockout cells manifested a significant decrease of the cell cycle lengths on all substrates $(p<0.01$ for each condition; Fig. 5A). In the third generation, no statistically significant differences could be discerned on the substrates PDL and LN1. In contrast, on Tnc the stretched cell cycle in the wildtype compared to $\mathrm{Tnc}^{-/-}$ aNSPCs $_{\text {late }}$ was obvious (wildtype: $18.8 \mathrm{~h}, \mathrm{n}=24, \mathrm{~N}=5$; knockout: $14.7 \mathrm{~h}, \mathrm{n}=23 ; \mathrm{N}=5, \mathrm{p}<0.001$; Fig. 5B). In the fourth generation the situation was analogous to the third generation. In particular, the significantly reduced cell cycle length of Tnc-deficient cells on a Tnc substrate persisted into the fourth generation (Fig. 
5C). Taken together, this analysis indicated that $\mathrm{TnC}^{-/-}$aNSPCs $s_{\text {late }}$ deriving from Tnc-deficient stem cell niches could not respond to distinct ECM signaling cues in the same manner as their wildtype counterparts.

\section{Functional analysis of aNSPC progeny in wildtype and Tnc-deficient cultures}

In the adult subependymal zone aNSPCs give rise to transient amplifying precursor cells and, eventually, to neuroblasts [14]. The latter migrate to the olfactory bulb where they differentiate to dopaminergic interneurons [36]. When the generation of neuroblasts was rated in our culture system, the incidence after 6 div ranged between $11,6 \pm 7,0 \%$ (mean $\pm S D, N=3$ ) and $16,3 \pm 3,7 \%(N=3)$ in wildtype and knockout cultures, respectively. The rather low frequency of neuroblasts may have resulted from the relatively short observation period of 6 days. The majority of stem cells thus may not have reached the end of their respective pedigrees. In order to obtain insight into the biological properties, the migratory activities of wildtype and knockout neuroblasts were compared in the PDL control condition. They could be distinguished in our system because the more undifferentiated states (aNSPC or TAP) were static and did not display a bipolar morphology. Neuroblasts were tracked in phase contrast images on PDL from the initial to the last movement of the time-lapse video recordings $(n=34, N=3 ;$ Fig. $6 \mathrm{~A})$. The time stamp indicates the temporal dimension as this factor is individual for the progeny of each lineage. The aNSPCs barely migrated as long as they were in a proliferative mode. The end point for movement analysis was defined as the moment when the neuroblast rested in a steady position and stopped migration. Wildtype cells covered a distance of $1522 \pm 156$ arbitrary units ( $A U, n=34, N=3$ ), while Tnc-deficient neuroblasts achieved a path length of $2418 \pm 204 \mathrm{AU}(\mathrm{n}=32$, mean \pm s.e.m., $N=3, p<0.001$, Fig. $6 \mathrm{~B})$. In theory, longer distances could be caused by a higher velocity or by longer duration of the motile activity. The velocity, however, was not different between both genotypes (wildtype: $0.45 \pm 0.04 \mathrm{AU} / \mathrm{min}, \mathrm{n}=34, \mathrm{~N}=3$; Tncknockout: $0.47 \pm 0.04 \mathrm{AU} / \mathrm{min}, \mathrm{n}=32, \mathrm{~N}=3$; mean \pm s.e.m.; Fig. $6 \mathrm{C}$ ). In order to explain this difference of the extent of cellular itineraries, the durations of migratory activity were evaluated for both genotypes. It emerged that the Tnc-deficient neuroblasts were motile for a mean time sequence of $5088 \pm 124 \mathrm{~min}(\mathrm{n}=$ $32, N=3)$, whereas wildtype neuroblasts moved for a mean of $3530 \pm 206 \min (n=34, N=3, p<0.001$; Fig. 6D) during the observation period. It appears that the wildtype cells paused significantly more often than the Tnc-deficient neuroblasts, which may reveal an anti-migratory effect of the glycoprotein on cell motility. While this functional trait of the generated neuroblasts was altered between the two genotypes, differentiation assays did not indicate a notable impact on cell fate (supplemental Fig. S1).

\section{Comparison of signaling pathway in the SEZ of Tnc-knockout mice in vivo}

It was known from previous studies that Tnc intervenes in critical signaling pathways [18]. Therefore, protein samples collected from the lateral ventricular wall of 10-week old wildtype and knockout mice were analyzed by Western blotting (Fig. 7A). The astrocyte marker GFAP that is strongly expressed in type B stem cells [6] was decreased in Tnc-knockout samples (wildtype: $15.8 \pm 5.8 \mathrm{AU}, n=5, N=5$; Tnc knockout: $5.8 \pm 1.9 \mathrm{AU}, \mathrm{n}=3, \mathrm{~N}=3, \mathrm{p}=0.14$; Fig. 7B). The stem cell marker Sox2 varied barely between wildtype and knockout (wildtype: $0.61 \pm 0.06 \mathrm{AU}, \mathrm{n}=5, \mathrm{~N}=5$; knockout: $0.73 \pm 0.03 \mathrm{AU}, \mathrm{n}=3, \mathrm{~N}=3$; Fig. 
7C). Thus, the classical stem cell markers were negligibly affected by the depletion of Tnc from the aNSPC niche of the lateral ventricle. The same set of protein samples was also analyzed with emphasis on developmentally relevant signal transduction pathways. A particular attention was devoted to mechanisms that regulate cell cycle progression, as this process was modified

by Tnc deficiency in the in vitro assays. The ERK signaling path was assessed by determining the level of phosphorylated ERK (pERK), as normalized to the corresponding total ERK1/2 (tERK) signal (wildtype: $2.6 \pm 1.0 \mathrm{AU}, \mathrm{n}=5, \mathrm{~N}=5$; Tnc knockout: $13.8 \pm 4.7 \mathrm{AU}, \mathrm{n}=3, \mathrm{~N}=3, \mathrm{p}=0.07$ in Mann-Whitney U test; Fig. 7D). The seeming difference of activation in the knockout did not, however, achieve significance (Fig. 7D).

Furthermore, the Notch/delta pathway was examined that is involved in the maintenance of the aNSPC compartment [37]. The proportion of cleaved Notch1 receptor (Notch intracellular domain, NICD) serves as an indicator of the activation of this pathway and was normalized with regard to the total amount of Notch1. No modification could be found (wildtype: $0.057 \pm 0.004 \mathrm{AU}, \mathrm{n}=5, \mathrm{~N}=5$; knockout: $0.065 \pm 0.006$ $A U, n=3, N=3$; Fig. 7D). The Notch/delta pathway controls downstream the transcription factor hairy/enhancer of split (Hes5) [38]. The message level of Hes 5 was monitored by RT-PCR. Interestingly, an increased expression of Hes 5 was measured in tissue samples of Tnc-knockout mice at 10-weeks of age (wildtype: $0.19 \pm 0.03 \mathrm{AU}, \mathrm{n}=4, \mathrm{~N}=4$; knockout: $0.32 \pm 0.12 \mathrm{AU}, \mathrm{n}=4, \mathrm{~N}=4, \mathrm{p}=0.686$; Fig. 7E). A similar difference could also be detected in cultures of cortical neurospheres derived from E15 mice (wildtype: $0.91 \pm 0.18 \mathrm{AU}, \mathrm{n}=4, \mathrm{~N}=4$; knockout: $1.80 \pm 0.25, \mathrm{n}=3, \mathrm{~N}=3, \mathrm{p}=0.057$; Fig. 7E).

As Tnc affects the duration of the cell cycle, genes involved in its regulation were of interest. In a previous study using gene arrays, the expression level of some cell cycle-related genes was found modified in the spinal cord of embryonic Tnc-deficient mice [21]. The cytoskeleton-associated protein 2-like protein (Ckap2l/Radmis) is required for mitotic spindle formation and cell cycle progression in neural progenitor cells [39]. We found a reduction of Ckap2I mRNA expression in cortical neurosphere cultures of E15 Tncknockout mice (wildtype: $0.32 \pm 0.09 \mathrm{AU}, \mathrm{n}=4, \mathrm{~N}=4$; Tnc knockout: $0.19 \pm 0.02 \mathrm{AU}, \mathrm{n}=3, \mathrm{~N}=3, p=0.847$; Fig. 7E'). From our results, we assume that Tnc deficiency has an impact on signaling pathways that are relevant for the regulation of cell proliferation and cell cycle progression. The detailed mechanism and participating proteins remain to be investigated in the future.

\section{Discussion}

Our results show that the glycoprotein Tnc has a strong influence on the proliferation of aNSPCs obtained from the SEZ investigated by time-lapse video microscopy and lineage tracking in vitro. The cultivation of SEZ cultures in suspension revealed a reduced neurosphere formation capacity in Tnc-deficient cultures in response to EGF treatment. This could result from a decreased expression level of the EGFR documented on the mRNA and protein level. A link between Tnc and EGFR expression has been reported previously in embryonic neural progenitors, as mice lacking Tnc experienced a delayed acquisition of this receptor [25]. In adult mice, the presence of the EGFR discriminates between quiescent (EGFR-negative) and active (EGFR-positive) aNSPCs [40,41]. Thus, a reduced responsiveness to EGF might reflect a 
shifted proportion between these two subpopulations of aNSPCs and does not necessarily point towards a generally reduced stem cell pool in Tnc-deficient mice. This explanation is in agreement with an in vivo approach of stem cell quantification in the adult Tnc-knockout niche using BrdU labeling, where no striking changes were detected in comparison to $\mathrm{TnC}^{+/-}$heterozygous mice [42].

A recent study reported a faster cell cycle progression in Tnc-deficient spinal cord progenitors isolated from E15 mice [26]. This finding obtains further support by our observation of shorter cell cycles also in aNSPCs from the SEZ in adult Tnc-knockout mice. The influence of Tnc on cell proliferation is controversially being discussed, as Tnc elimination caused opposite results, depending on the experimental context and cell type $[43,44]$. The cultivation on a Tnc substrate accelerated the cell cycle in the majority of proliferating cells but elongated it in the subset of slow-dividing aNSPCs $s_{\text {late. }}$. This subpopulation behaved as expected for genuine aNSPCs, distinct from fate-restricted progenitors [8]. Both proliferating populations may be considered as progenitors isolated at different stages of their respective lineage progression [9]. The opposite response to the ECM component Tnc might indicate differences in the receptor expression that eventually impact signaling mechanisms to alter cell cycle progression. This phenomenon was not noted in Tnc-knockout cultures where a compensation caused by coated Tnc failed. It seems that the absence of Tnc in the adult neural stem cell niche of knockout mice desensitized the aNSPCs for this compound. Another possible explanation would be a threshold effect, where the coating protein on the culture surface has to be supplemented by cell secreted Tnc protein to reach an effective concentration. It remains still elusive whether Tnc expression in the SEZ of adult mice has the function of maintaining the stem cell pool. A decreased amount of asymmetric cell divisions and accompanied increased percentage of neuroblast generation after 6 days in vitro (our unpublished observations) corroborates this hypothesis, because this would favor a faster depletion of the stem cell pool in Tnc-deficient populations. Furthermore, we can conclude from our data that Tnc-knockout aNSPCs $_{\text {late }}$ enter the cell cycle earlier than their wildtype counterparts, indicating that their activation happens faster. This strengthens the idea of Tnc as a promoter of the quiescent state. This effect could

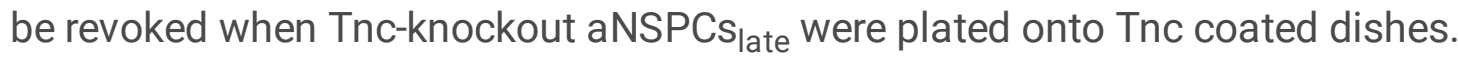

It has been described for several cell types that LN1 promotes cell proliferation and neurogenesis [3032]. The accelerating effect on cell cycle progression was also observed in our experiments for the mitotic population of the primary SEZ cultures from wildtype and Tnc-knockout mice. For both ECM compounds of interest investigated in this study, integrins represent important receptors $[45,46]$. Thus, it is conceivable that the regulatory effects enacted by these substrate proteins are mediated by integrins. This most probably involves different heterodimeric receptors, as the reaction of slow-dividing aNSPCs $s_{\text {late }}$ to the LN1 and Tnc substrates was not congruent. In support of this assumption, a distinct expression pattern of integrin variants during lineage progression has been reported [47].

Several reports suggest that Tnc has an impact on migration $[48,49]$. In particular in pathologic contexts such as cancer, a promoting effect on migration and metastasis has been attributed to Tnc [50,51], which might be mediated via integrins $[52,53]$. Our in vitro experiments with aNSPCs from the $\mathrm{Tnc}^{-/-}$deficient 
SEZ revealed increased migration trajectories of neuroblasts that were caused by elongation of movement episodes. This is reminiscent of increased migration of oligodendrocyte precursors observed in Tnc-deficient rats [24]. Tnc expression was found in the pathway of the rostral migratory stream [42] where neuroblasts migrate along to colonize the olfactory bulb and integrate into local neuronal networks [54]. The Tnc glycoprotein might have a guidance function there as it serves as inhibitory boundary molecule for olfactory sensory neurons [55]. Along these lines, early studies on Tnc in cell cultures characterized the glycoprotein as anti-adhesive [56,34]. Anti-adhesion was also seen in the videos generated in this study with respect to aNSPCs, although not as pronounced as for embryonic neural progenitors (unpublished observations). Changes of the intensity of substrate adhesion might be an indirect cause of the observed results and has been discussed as a potential mechanism to influence migration and proliferation [57].

The altered GFAP protein level observed in in vivo SEZ samples points to structural changes in the niche of Tnc-knockout mice. GFAP is a marker that is expressed by niche astrocytes and aNSPCs. Therefore, both cell populations could be responsible for variations of GFAP expression. Minor structural changes have already been described by previous studies of the SEZ niche in $\mathrm{Tnc}^{-/-}$knockout animals [42]. The latter study for example described an increased number of neuroblast clusters around the lateral ventricle of $\mathrm{Tnc}^{-/-}$null mice. This is in agreement with our observation of a higher rate of neuroblast generation by $\mathrm{TnC}^{-/-}$aNSPCs in vitro (E. Schaberg, unpublished observations).

In order to gain mechanistic insight, we investigated a potential intervention of Tnc in signaling pathways in the adult SEZ. Interestingly, the ERK pathway activity was altered upon Tnc knockout. This pathway is linked to the regulation of migration in numerous contexts [58], which may mechanistically explain the enhanced migration of knockout cells observed here. The increased rate of phosphorylated ERK may also be the cause for faster cell cycling as this pathway is known to regulate cell cycle progression and transition from $\mathrm{G} 1$ to S-phase $[59,60]$. Activation of the ERK1/2 pathway in primary embryonic cortical neurons by the synthetic biomimetic VSWRAPTA peptide derived from the primary Tnc sequence has been reported [28]. Taken together, these findings suggest of the ERK1/2 pathway in mediating reactions to $\mathrm{Tnc}$ in the niche environment.

With regard to further downstream mechanisms related to cell cycle control, the cytoskeleton-associated protein 2-like protein (Ckap2l/Radmis) appeared reduced in $\mathrm{TnC}^{-/-}$SEZ knockout tissue, as had been described in embryonic spinal cord based on transcriptome analysis [21].

Taken together, our data suggest that Tnc intervenes in the control of cell cycle length. This holds true for both the embryonic stem cell compartment as well as the aNSPCs. Defined ECM components such as Tnc and LN1, both parts of the adult stem cell niche, influence the proliferation dynamics of the dividing aNSPC population. Closer inspection revealed different effects depending on lineage progression of aNSPCs, with particular features of the slowly dividing aNSPCslate subpopulation that closely resembles type $B$ stem cells of the niche. The impact of the ECM most probably is mediated by alterations in key signaling pathways of cell cycle regulation in the Tnc-knockout mice in vivo.

Page 15/31 


\section{Conclusions}

In summary, our study provides novel insights into the role of Tnc in the stem cell niche of the adult SEZ and strongly underlines a regulatory role in cell cycle progression of aNSPCs. Tnc intervenes in cell cycle progression and its elimination consequently reduces cell cycle length in aNSPCs. This most probably involves the pERK signaling pathway. A subcategory of late dividing adult neural stem cells could be identified in cell tracking that putatively represents slowly dividing aNSPCs. Tnc ablation did not modify the differentation of aNSPCs into distinct lineages. However, Tnc shortened the migratory activity of neuroblasts, the major offspring of aNSPCs, by reducing the duration of migratory episodes.

\section{Declarations}

\section{Acknowledgements}

The Tnc knockout line was generously provided by Prof. Fässler (MPI Biochemistry, Martinsried, Germany)[33]. We thank Marion Völzkow and Anke Mommsen for technical support with sectioning and cell culture, respectively.

\section{Author Contributions}

Conceptualization, A.F. and E.S.; Formal Analysis, E.S. and A.F.; Funding Acquisition, A.F.; Methodology, E.S., A.F. and M.G.; Writing-Original Draft, E.S. and A.F.; Writing-Review \& Editing, A.F., M.G. and E.S. All authors have read and agreed to the published version of the manuscript.

\section{Funding}

We gratefully acknowledge grant support from the German Research Foundation (DFG: SPP-1757, FA 159/20-1,2).

\section{Data Availability}

The materials used in this study are available to any qualified researcher upon reasonable request addressed to A.F.

\section{Conflicts of Interest}

The authors declare no conflicts of interest.

\section{Ethical approval}

The present study was carried out in accordance with the European Council Directive of September 22, 2010 (2010/63/EU) for care of laboratory animals and approved by the animal care committee of North Rhine-Westphalia, Germany, based at the LANUV (Landesamt für Umweltschutz, Naturschutz und Verbraucherschutz, Nordrhein-Westphalen, D-45659 Recklinghausen, Germany). The study was supervised by the animal welfare commissioner of Ruhr-University. 


\section{References}

1. Lim DA, Alvarez-Buylla A (2016) The Adult Ventricular-Subventricular Zone (V-SVZ) and Olfactory Bulb (OB) Neurogenesis. Cold Spring Harb Perspect Biol 8 (5). doi:10.1101/cshperspect.a018820

2. Goncalves JT, Schafer ST, Gage FH (2016) Adult Neurogenesis in the Hippocampus: From Stem Cells to Behavior. Cell 167 (4):897-914. doi:10.1016/j.cell.2016.10.021

3. Mirzadeh Z, Merkle FT, Soriano-Navarro M, Garcia-Verdugo JM, Alvarez-Buylla A (2008) Neural stem cells confer unique pinwheel architecture to the ventricular surface in neurogenic regions of the adult brain. Cell stem cell 3 (3):265-278. doi:10.1016/j.stem.2008.07.004

4. Shen Q, Wang Y, Kokovay E, Lin G, Chuang SM, Goderie SK, Roysam B, Temple S (2008) Adult SVZ stem cells lie in a vascular niche: a quantitative analysis of niche cell-cell interactions. Cell stem cell 3 (3):289-300. doi:10.1016/j.stem.2008.07.026

5. Beckervordersandforth R, Tripathi P, Ninkovic J, Bayam E, Lepier A, Stempfhuber B, Kirchhoff F, Hirrlinger J, Haslinger A, Lie DC, Beckers J, Yoder B, Irmler M, Gotz M (2010) In vivo fate mapping and expression analysis reveals molecular hallmarks of prospectively isolated adult neural stem cells. Cell stem cell 7 (6):744-758. doi:10.1016/j.stem.2010.11.017

6. Doetsch F, Caille I, Lim DA, Garcia-Verdugo JM, Alvarez-Buylla A (1999) Subventricular zone astrocytes are neural stem cells in the adult mammalian brain. Cell 97 (6):703-716. doi:10.1016/s00928674(00)80783-7

7. Kriegstein A, Alvarez-Buylla A (2009) The glial nature of embryonic and adult neural stem cells. Annu Rev Neurosci 32:149-184. doi:10.1146/annurev.neuro.051508.135600

8. Ortega F, Costa MR, Simon-Ebert T, Schroeder T, Gotz M, Berninger B (2011) Using an adherent cell culture of the mouse subependymal zone to study the behavior of adult neural stem cells on a single-cell level. Nat Protoc 6 (12):1847-1859. doi:10.1038/nprot.2011.404

9. Costa MR, Ortega F, Brill MS, Beckervordersandforth R, Petrone C, Schroeder T, Gotz M, Berninger B (2011) Continuous live imaging of adult neural stem cell division and lineage progression in vitro. Development 138 (6):1057-1068. doi:10.1242/dev.061663

10. Lois C, Alvarez-Buylla A (1994) Long-distance neuronal migration in the adult mammalian brain. Science 264 (5162):1145-1148. doi:10.1126/science.8178174

11. Reynolds BA, Weiss S (1992) Generation of neurons and astrocytes from isolated cells of the adult mammalian central nervous system. Science 255 (5052):1707-1710. doi:10.1126/science.1553558

12. Laywell ED, Rakic P, Kukekov VG, Holland EC, Steindler DA (2000) Identification of a multipotent astrocytic stem cell in the immature and adult mouse brain. Proceedings of the National Academy of 
Sciences of the United States of America 97 (25):13883-13888. doi:10.1073/pnas.250471697

13. Lim DA, Alvarez-Buylla A (1999) Interaction between astrocytes and adult subventricular zone precursors stimulates neurogenesis. Proceedings of the National Academy of Sciences of the United States of America 96 (13):7526-7531. doi:10.1073/pnas.96.13.7526

14. Doetsch F, Petreanu L, Caille I, Garcia-Verdugo JM, Alvarez-Buylla A (2002) EGF converts transitamplifying neurogenic precursors in the adult brain into multipotent stem cells. Neuron 36 (6):1021-1034

15. Chermnykh E, Kalabusheva E, Vorotelyak E (2018) Extracellular Matrix as a Regulator of Epidermal Stem Cell Fate. Int J Mol Sci 19 (4). doi:10.3390/ijms19041003

16. Wang T, Nanda SS, Papaefthymiou GC, Yi DK (2020) Mechanophysical Cues in Extracellular Matrix Regulation of Cell Behavior. Chembiochem 21 (9):1254-1264. doi:10.1002/cbic.201900686

17. Besser M, Jagatheaswaran M, Reinhard J, Schaffelke P, Faissner A (2012) Tenascin C regulates proliferation and differentiation processes during embryonic retinogenesis and modulates the dedifferentiation capacity of Muller glia by influencing growth factor responsiveness and the extracellular matrix compartment. Dev Biol 369 (2):163-176. doi:10.1016/j.ydbio.2012.05.020

18. Faissner A, Roll L, Theocharidis U (2017) Tenascin-C in the matrisome of neural stem and progenitor cells. Molecular and cellular neurosciences 81:22-31. doi:10.1016/j.mcn.2016.11.003

19. Gotz M, Stoykova A, Gruss P (1998) Pax6 controls radial glia differentiation in the cerebral cortex. Neuron 21 (5):1031-1044

20. von Holst A, Egbers U, Prochiantz A, Faissner A (2007) Neural stem/progenitor cells express 20 tenascin $\mathrm{C}$ isoforms that are differentially regulated by Pax6. The Journal of biological chemistry 282 (12):9172-9181

21. Karus M, Denecke B, ffrench-Constant C, Wiese S, Faissner A (2011) The extracellular matrix molecule tenascin $\mathrm{C}$ modulates expression levels and territories of key patterning genes during spinal cord astrocyte specification. Development 138 (24):5321-5331. doi:dev.067413 [pii] 10.1242/dev.067413

22. Kjell J, Fischer-Sternjak J, Thompson AJ, Friess C, Sticco MJ, Salinas F, Cox J, Martinelli DC, Ninkovic J, Franze K, Schiller HB, Gotz M (2020) Defining the Adult Neural Stem Cell Niche Proteome Identifies Key Regulators of Adult Neurogenesis. Cell stem cell 26 (2):277-293 e278. doi:10.1016/j.stem.2020.01.002

23. Chiquet-Ehrismann R, Orend G, Chiquet M, Tucker RP, Midwood KS (2014) Tenascins in stem cell niches. Matrix biology : journal of the International Society for Matrix Biology 37:112-123. doi:10.1016/j.matbio.2014.01.007

24. Garcion E, Faissner A, ffrench-Constant C (2001) Knockout mice reveal a contribution of the extracellular matrix molecule tenascin- $C$ to neural precursor proliferation and migration. Development 128 
25. Garcion E, Halilagic A, Faissner A, ffrench-Constant C (2004) Generation of an environmental niche for neural stem cell development by the extracellular matrix molecule tenascin C. Development 131 (14):3423-3432

26. May M, Denecke B, Schroeder T, Gotz M, Faissner A (2018) Cell tracking in vitro reveals that the extracellular matrix glycoprotein Tenascin- $\mathrm{C}$ modulates cell cycle length and differentiation in neural stem/progenitor cells of the developing mouse spinal cord. Biol Open 7 (7). doi:10.1242/bio.027730

27. Czopka T, von Holst A, ffrench-Constant C, Faissner A (2010) Regulatory mechanisms that mediate tenascin C-dependent inhibition of oligodendrocyte precursor differentiation. J Neurosci 30 (37):1231012322. doi:30/37/12310 [pii] 10.1523/JNEUROSCI.4957-09.2010

28. Jarocki M, Sallouh O, Weberskirch R, Faissner A (2019) The Tenascin-C-Derived Peptide VSWRAPTA Promotes Neuronal Branching Via Transcellular Activation of the Focal Adhesion Kinase (FAK) and the ERK1/2 Signaling Pathway In Vitro. Molecular neurobiology 56 (1):632-647. doi:10.1007/s12035-018$1108-7$

29. Nascimento MA, Sorokin L, Coelho-Sampaio T (2018) Fractone Bulbs Derive from Ependymal Cells and Their Laminin Composition Influence the Stem Cell Niche in the Subventricular Zone. J Neurosci 38 (16):3880-3889. doi:10.1523/JNEUROSCI.3064-17.2018

30. Ocalan M, Goodman SL, Kuhl U, Hauschka SD, von der Mark K (1988) Laminin alters cell shape and stimulates motility and proliferation of murine skeletal myoblasts. Dev Biol 125 (1):158-167. doi:10.1016/0012-1606(88)90068-1

31. Farrukh A, Ortega F, Fan W, Marichal N, Paez JI, Berninger B, Campo AD, Salierno MJ (2017) Bifunctional Hydrogels Containing the Laminin Motif IKVAV Promote Neurogenesis. Stem Cell Reports 9 (5):1432-1440. doi:10.1016/j.stemcr.2017.09.002

32. Hall PE, Lathia JD, Caldwell MA, Ffrench-Constant C (2008) Laminin enhances the growth of human neural stem cells in defined culture media. BMC Neurosci 9:71. doi:10.1186/1471-2202-9-71

33. Forsberg E, Hirsch E, Frohlich L, Meyer M, Ekblom P, Aszodi A, Werner S, Fassler R (1996) Skin wounds and severed nerves heal normally in mice lacking tenascin-C. Proceedings of the National Academy of Sciences of the United States of America 93 (13):6594-6599. doi:10.1073/pnas.93.13.6594

34. Faissner A, Kruse $\mathrm{J}(1990) \mathrm{J} 1 /$ tenascin is a repulsive substrate for central nervous system neurons. Neuron 5 (5):627-637

35. Gates MA, Thomas LB, Howard EM, Laywell ED, Sajin B, Faissner A, Gotz B, Silver J, Steindler DA (1995) Cell and molecular analysis of the developing and adult mouse subventricular zone of the cerebral hemispheres. J Comp Neurol 361 (2):249-266. doi:10.1002/cne.903610205 
36. Ming GL, Song H (2005) Adult neurogenesis in the mammalian central nervous system. Annu Rev Neurosci 28:223-250

37. Jang J, Byun SH, Han D, Lee J, Kim J, Lee N, Kim I, Park S, Ha S, Kwon M, Ahn J, Chung WJ, Kweon DH, Cho JY, Kim S, Yoon K (2014) Notch intracellular domain deficiency in nuclear localization activity retains the ability to enhance neural stem cell character and block neurogenesis in mammalian brain development. Stem cells and development 23 (23):2841-2850. doi:10.1089/scd.2014.0031

38. Sancho R, Blake SM, Tendeng C, Clurman BE, Lewis J, Behrens A (2013) Fbw7 repression by hes5 creates a feedback loop that modulates Notch-mediated intestinal and neural stem cell fate decisions. PLoS biology 11 (6):e1001586. doi:10.1371/journal.pbio.1001586

39. Yumoto T, Nakadate K, Nakamura Y, Sugitani Y, Sugitani-Yoshida R, Ueda S, Sakakibara S (2013) Radmis, a novel mitotic spindle protein that functions in cell division of neural progenitors. PLoS One 8 (11):e79895. doi:10.1371/journal.pone.0079895

40. Pastrana E, Cheng LC, Doetsch F (2009) Simultaneous prospective purification of adult subventricular zone neural stem cells and their progeny. Proceedings of the National Academy of Sciences of the United States of America 106 (15):6387-6392. doi:10.1073/pnas.0810407106

41. Fischer J, Beckervordersandforth R, Tripathi P, Steiner-Mezzadri A, Ninkovic J, Gotz M (2011) Prospective isolation of adult neural stem cells from the mouse subependymal zone. Nat Protoc 6 (12):1981-1989. doi:10.1038/nprot.2011.412

42. Kazanis I, Belhadi A, Faissner A, Ffrench-Constant C (2007) The adult mouse subependymal zone regenerates efficiently in the absence of tenascin-C. J Neurosci 27 (51):13991-13996

43. Huang W, Chiquet-Ehrismann R, Moyano JV, Garcia-Pardo A, Orend G (2001) Interference of tenascin$C$ with syndecan-4 binding to fibronectin blocks cell adhesion and stimulates tumor cell proliferation. Cancer Res 61 (23):8586-8594

44. Orend G, Huang W, Olayioye MA, Hynes NE, Chiquet-Ehrismann R (2003) Tenascin-C blocks cell-cycle progression of anchorage-dependent fibroblasts on fibronectin through inhibition of syndecan-4. Oncogene 22 (25):3917-3926. doi:10.1038/sj.onc.1206618

45. Gardiner NJ (2011) Integrins and the extracellular matrix: key mediators of development and regeneration of the sensory nervous system. Dev Neurobiol 71 (11):1054-1072. doi:10.1002/dneu.20950

46. Midwood KS, Chiquet M, Tucker RP, Orend G (2016) Tenascin-C at a glance. Journal of cell science 129 (23):4321-4327. doi:10.1242/jcs.190546

47. Kazanis I, Lathia JD, Vadakkan TJ, Raborn E, Wan R, Mughal MR, Eckley DM, Sasaki T, Patton B, Mattson MP, Hirschi KK, Dickinson ME, ffrench-Constant C (2010) Quiescence and activation of stem and precursor cell populations in the subependymal zone of the mammalian brain are associated with 
distinct cellular and extracellular matrix signals. J Neurosci 30 (29):9771-9781.

doi:10.1523/JNEUROSCI.0700-10.2010

48. Faissner A (1997) The tenascin gene family in axon growth and guidance. Cell and tissue research 290 (2):331-341

49. Akbareian SE, Nagy N, Steiger CE, Mably JD, Miller SA, Hotta R, Molnar D, Goldstein AM (2013) Enteric neural crest-derived cells promote their migration by modifying their microenvironment through tenascinC production. Dev Biol 382 (2):446-456. doi:10.1016/j.ydbio.2013.08.006

50. Cai J, Du S, Wang H, Xin B, Wang J, Shen W, Wei W, Guo Z, Shen X (2017) Tenascin-C induces migration and invasion through JNK/C-Jun signalling in pancreatic cancer. Oncotarget 8 (43):7440674422. doi:10.18632/oncotarget.20160

51. Sun Z, Schwenzer A, Rupp T, Murdamoothoo D, Vegliante R, Lefebvre O, Klein A, Hussenet T, Orend G (2018) Tenascin-C Promotes Tumor Cell Migration and Metastasis through Integrin alpha9beta1Mediated YAP Inhibition. Cancer Res 78 (4):950-961. doi:10.1158/0008-5472.CAN-17-1597

52. Naik A, Al-Yahyaee A, Abdullah N, Sam JE, Al-Zeheimi N, Yaish MW, Adham SA (2018) Neuropilin-1 promotes the oncogenic Tenascin-C/integrin beta3 pathway and modulates chemoresistance in breast cancer cells. BMC Cancer 18 (1):533. doi:10.1186/s12885-018-4446-y

53. Zhang Z, Yu B, Gu Y, Zhou S, Qian T, Wang Y, Ding G, Ding F, Gu X (2016) Fibroblast-derived tenascin-C promotes Schwann cell migration through beta1-integrin dependent pathway during peripheral nerve regeneration. Glia 64 (3):374-385. doi:10.1002/glia.22934

54. Ming GL, Song H (2011) Adult neurogenesis in the mammalian brain: significant answers and significant questions. Neuron 70 (4):687-702. doi:10.1016/j.neuron.2011.05.001

55. Treloar HB, Ray A, Dinglasan LA, Schachner M, Greer CA (2009) Tenascin-C is an inhibitory boundary molecule in the developing olfactory bulb. J Neurosci 29 (30):9405-9416. doi:10.1523/JNEUROSCI.235609.2009

56. Chiquet-Ehrismann R, Mackie EJ, Pearson CA, Sakakura T (1986) Tenascin: an extracellular matrix protein involved in tissue interactions during fetal development and oncogenesis. Cell 47 (1):131-139. doi:10.1016/0092-8674(86)90374-0

57. Murphy-Ullrich JE (2001) The de-adhesive activity of matricellular proteins: is intermediate cell adhesion an adaptive state? J Clin Invest 107 (7):785-790. doi:10.1172/JCl12609

58. Huang C, Jacobson K, Schaller MD (2004) MAP kinases and cell migration. Journal of cell science 117 (Pt 20):4619-4628. doi:10.1242/jcs.01481 
59. Meloche S, Pouyssegur J (2007) The ERK1/2 mitogen-activated protein kinase pathway as a master regulator of the G1- to S-phase transition. Oncogene 26 (22):3227-3239. doi:10.1038/sj.onc.1210414

60. Chambard JC, Lefloch R, Pouyssegur J, Lenormand P (2007) ERK implication in cell cycle regulation. Biochim Biophys Acta 1773 (8):1299-1310. doi:10.1016/j.bbamcr.2006.11.010

\section{Figures}

A
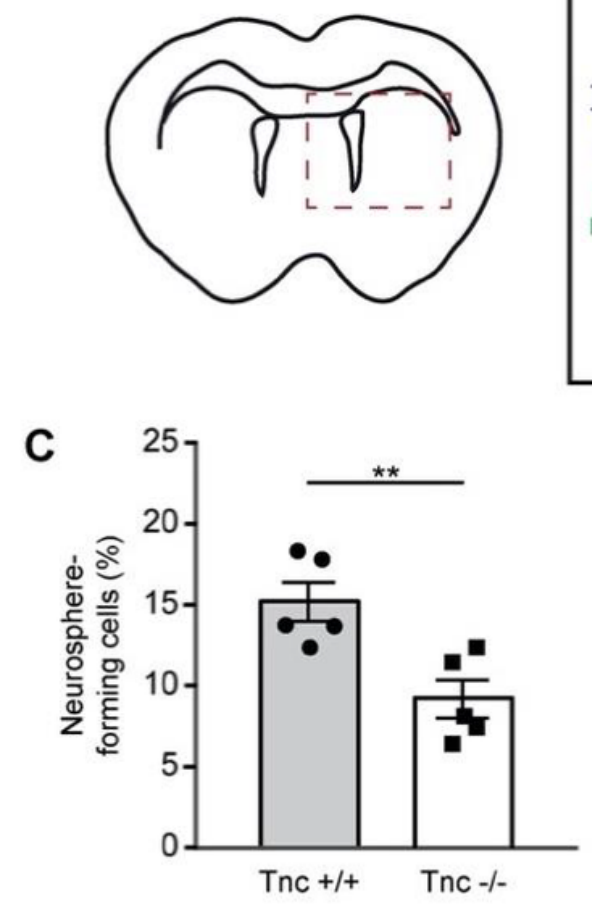
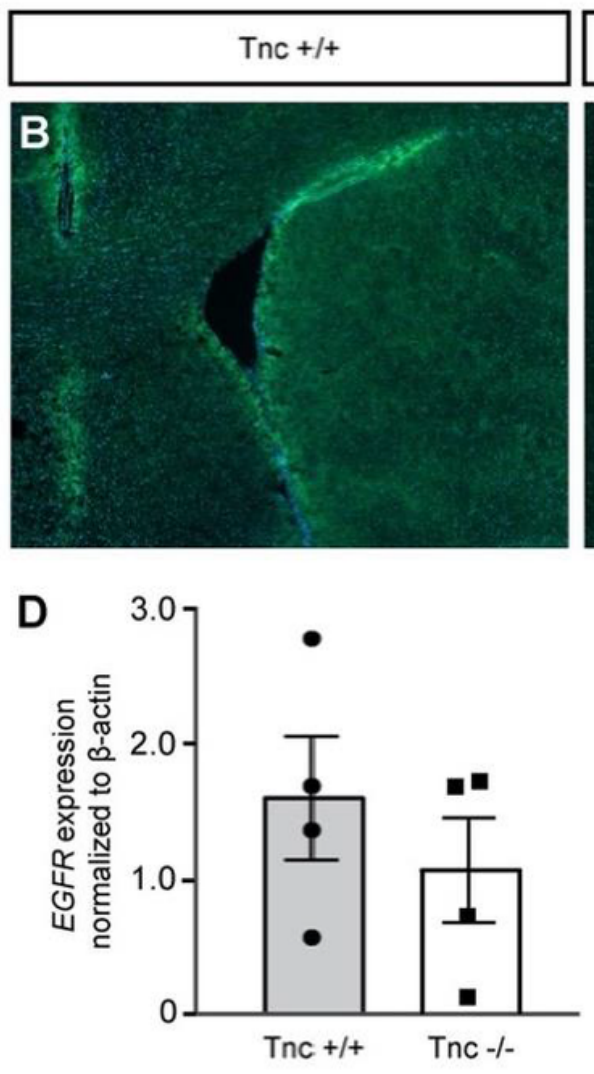
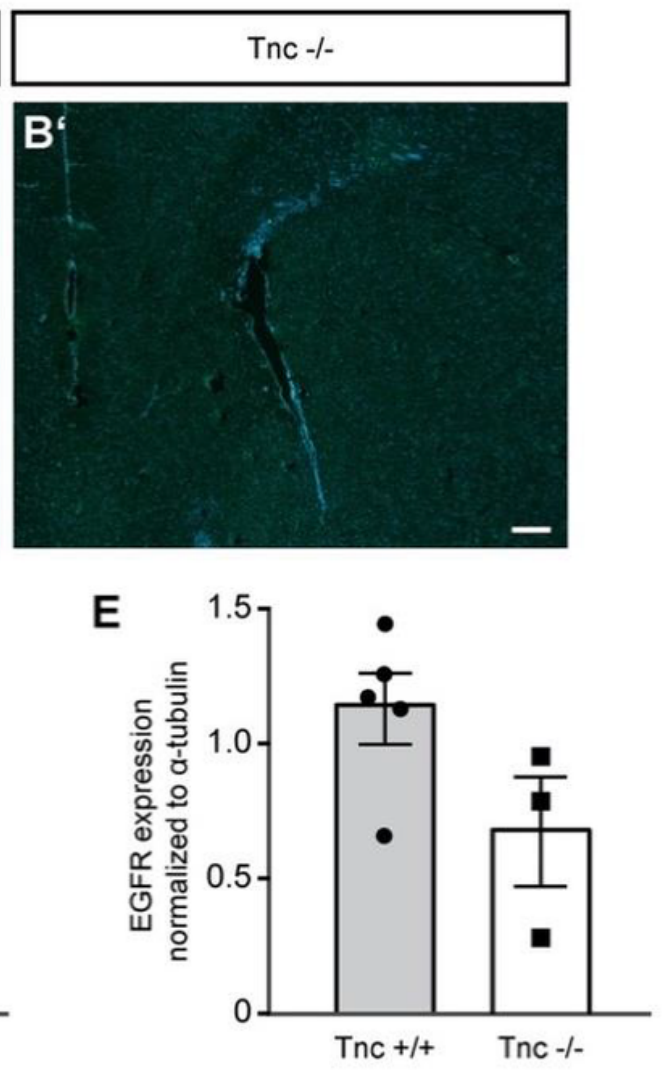

\section{Figure 1}

Adult neural stem cells isolated from Tnc-deficient mice exhibit a reduced neurosphere-formation capacity in vitro. The scheme depicted in (A) shows the contour of an adult brain in frontal sections with the two triangularly formed lateral ventricles and the curved structure of the corpus callosum above them. The red dotted line marks the detail that is illustrated in the immunohistochemical staining in ( $B$ and $\left.B^{\prime}\right)$. In the control (B), the distribution of the Tnc glycoprotein at the age of P70 can be detected around the lateral ventricle as well as around the third ventricle by polyclonal anti-Tnc antibodies. ( $\left.B^{\prime}\right)$ shows the same staining in a Tnc-deficient animal. There is no fluorescent signal detectable, which supports the specificity of the antibody and confirms the efficient knockout. Scale bar: $200 \mu \mathrm{m}$. (C) Adult neural stem cells isolated from 10-weeks old mice were cultivated in presence of $20 \mathrm{ng} / \mathrm{ml}$ EGF. The percentage of plated cells generating neurospheres after 7 days in vitro is significantly reduced in Tnc-knockout mice $(N=5)$. An unpaired two-tailed student's t-test was assessed for the statistics ( $* \star p<0.01)$. (D) RT-PCR analysis of isolated SEZ tissue showed a reduced expression of the required EGF receptor on mRNA level 
in vivo $(N=4)$. (E) The PCR result is supported by Western blot analysis of the EGF receptor, which verified a trend towards reduced expression also on the protein level (wildtype $\mathrm{N}=5$, Tnc knockout $\mathrm{N}=3$ ). Data are presented as mean \pm s.e.m. For D-E, the Mann-Whitney U-test was used for statistical analysis.
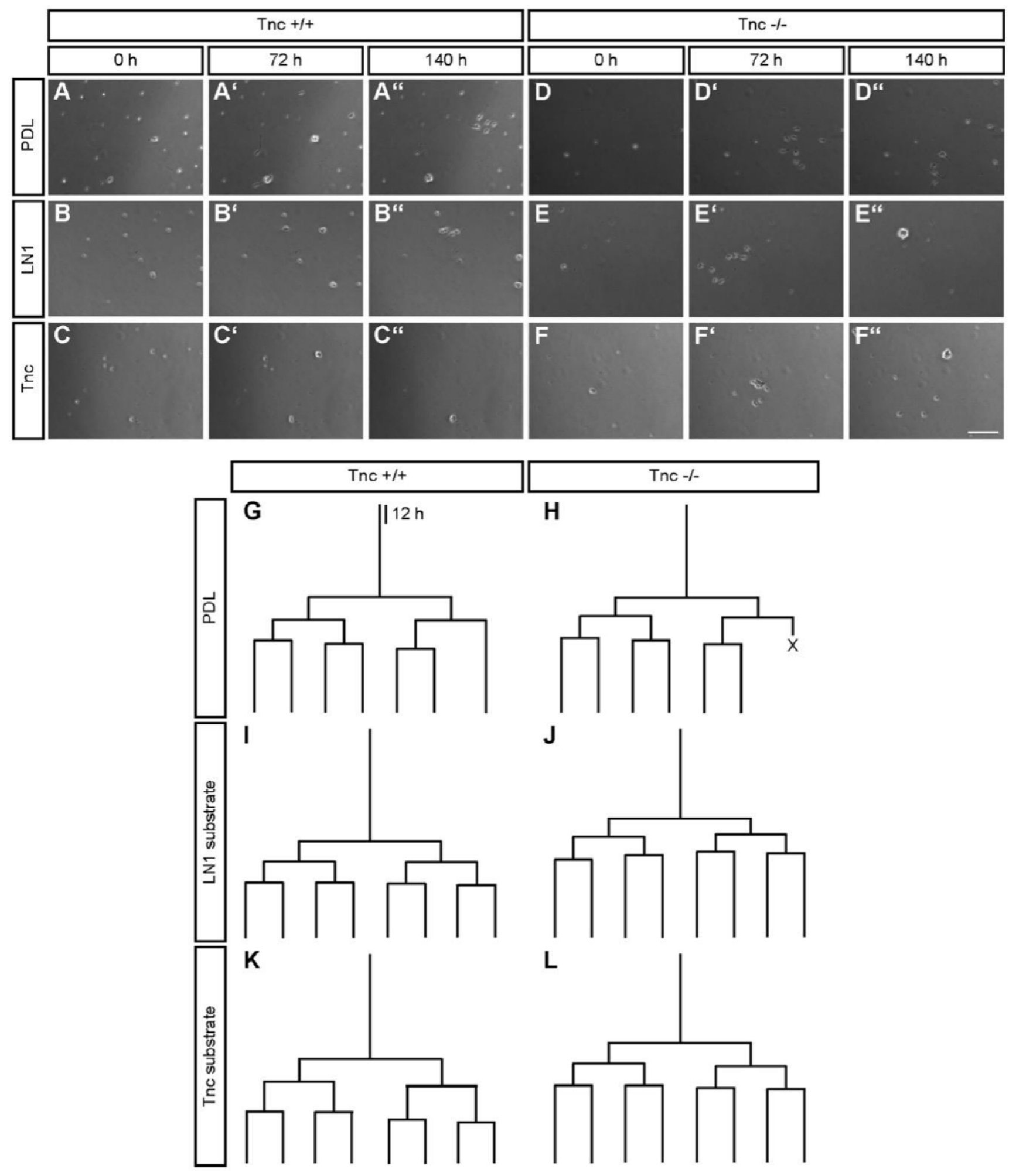

Figure 2

Phase contrast images and exemplary lineage trees of wildtype and Tnc-deficient SEZ cells on three experimentally tested substrates using time-lapse video microscopy over 6 div. For each condition, the 
time series depicts the identical field of view. (A-C) Phase contrast images of wildtype cells in all three conditions. The cells generally showed good adherence and survival rates. Proliferation events were visible after $72 \mathrm{~h}$, when first cell assemblies could be observed. After $140 \mathrm{~h}$, numerous cells appeared branched. Cultivation on Tnc coated PDL also led to cell proliferation. However, increased cell loss and the tendency to cell aggregation with diminished adhesion to the culture plate were observed in this condition. (D-F) Tnc-deficient cells also showed satisfying adhesion in the control condition and fast proliferation within $72 \mathrm{~h}$. In the next three days, cells on LN1 and Tnc started to cluster, which reduced the adhesion to the culture plate ( $E^{\prime \prime}$ and F"). Scale bar: $150 \mu \mathrm{m}$. (G-L) Exemplary pedigrees of individual mother cells in each condition monitored by lineage tracking are shown. Each lineage tree traces the proliferation of an initial mother cell to map the whole progeny that was generated within 140 hours of time-lapse video microscopy. Every branching point marks a cell division event and the length of the branches is proportional to the corresponding cell cycle duration. An ' $X$ ' marks the death of a daughter cell. 

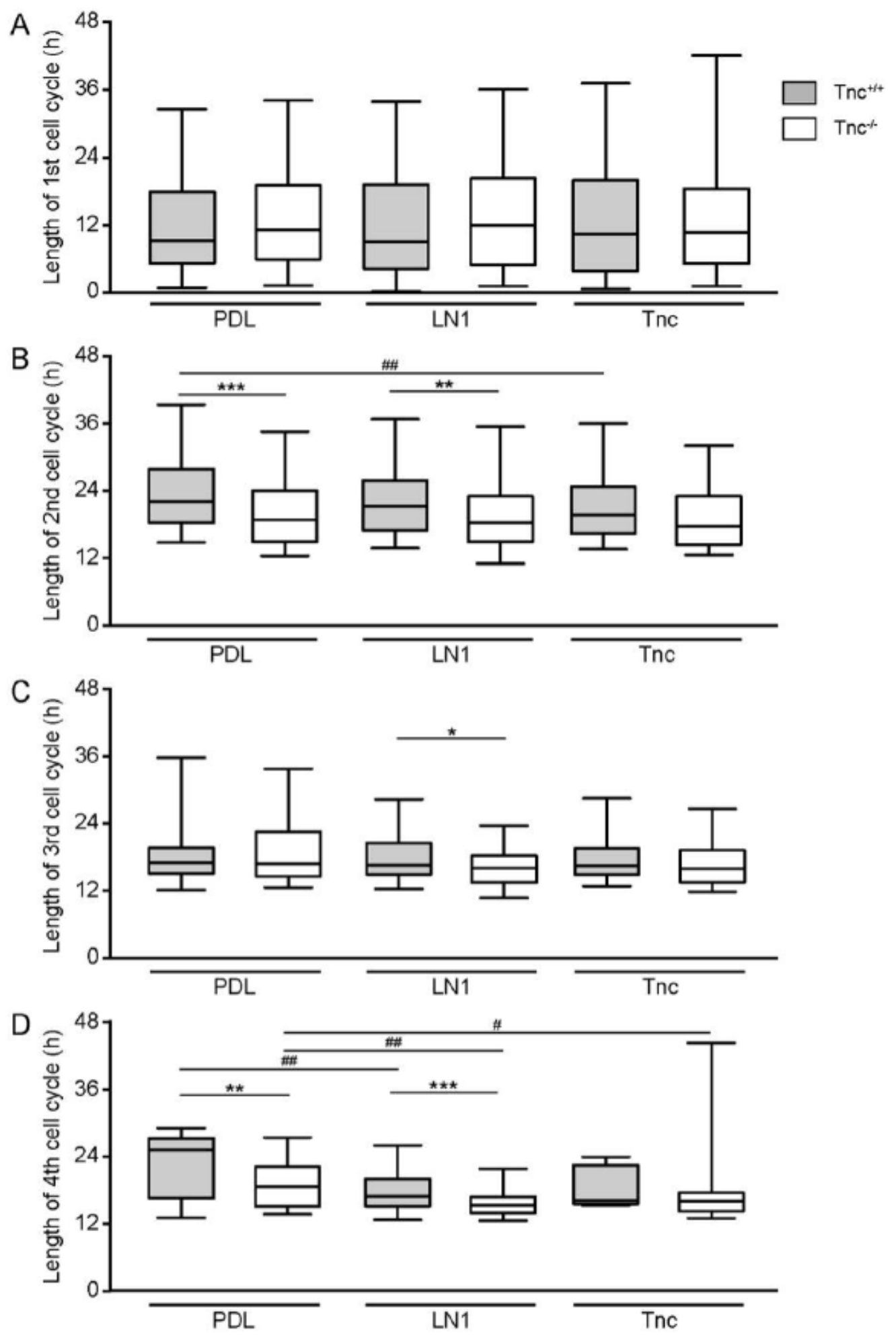

\section{Figure 3}

Cell cycle length of proliferative populations is reduced in Tnc-deficient SEZ cultures. (A) Cell cycle length of the 1 st generation in vitro. Please note that in this special case only the endpoint could be determined, resulting in a broader scattering of the data points. (B) Graphs display the results for the 2 nd generation in vitro. The cell cycle of wildtype aNSPCs was significantly accelerated on Tnc coated culture dishes. Tnc-deficient cells divided faster on the PDL control and on LN1, but not on Tnc substrate. (C) Illustrates 
results for the 3rd generation in vitro where cell cycle lengths were reduced in Tnc-deficient cells on the LN1 substrate compared to the wildtype. (D) Represents the results of the 4th generation in vitro. Wildtype cells displayed a shorter cell cycle on LN1, whereas knockout cells divided faster on both LN1 and Tnc. A significantly accelerated cell cycle was also observed in Tnc-knockout cells in comparison to their wildtype equivalent in the control condition and on the LN1 substrate. Five biologically independent experiments were performed $(\mathrm{N}=5)$. Every observed cell division in each video was included in the analysis $(n=7-185)$. More detailed information concerning the data set is available in supplemental table 2. Data are presented as box-whisker-plots with 5-95\% percentiles. The Kruskal-Wallis test with Dunn's multiple comparison post-test was used for statistical analysis of differences between the substrates (* $p<0.05, * \star p<0.01)$. The Mann-Whitney U-tests were performed for statistical analysis between the genotypes $(* p<0.05, * * p<0.01, * \star \star p<0.001)$.
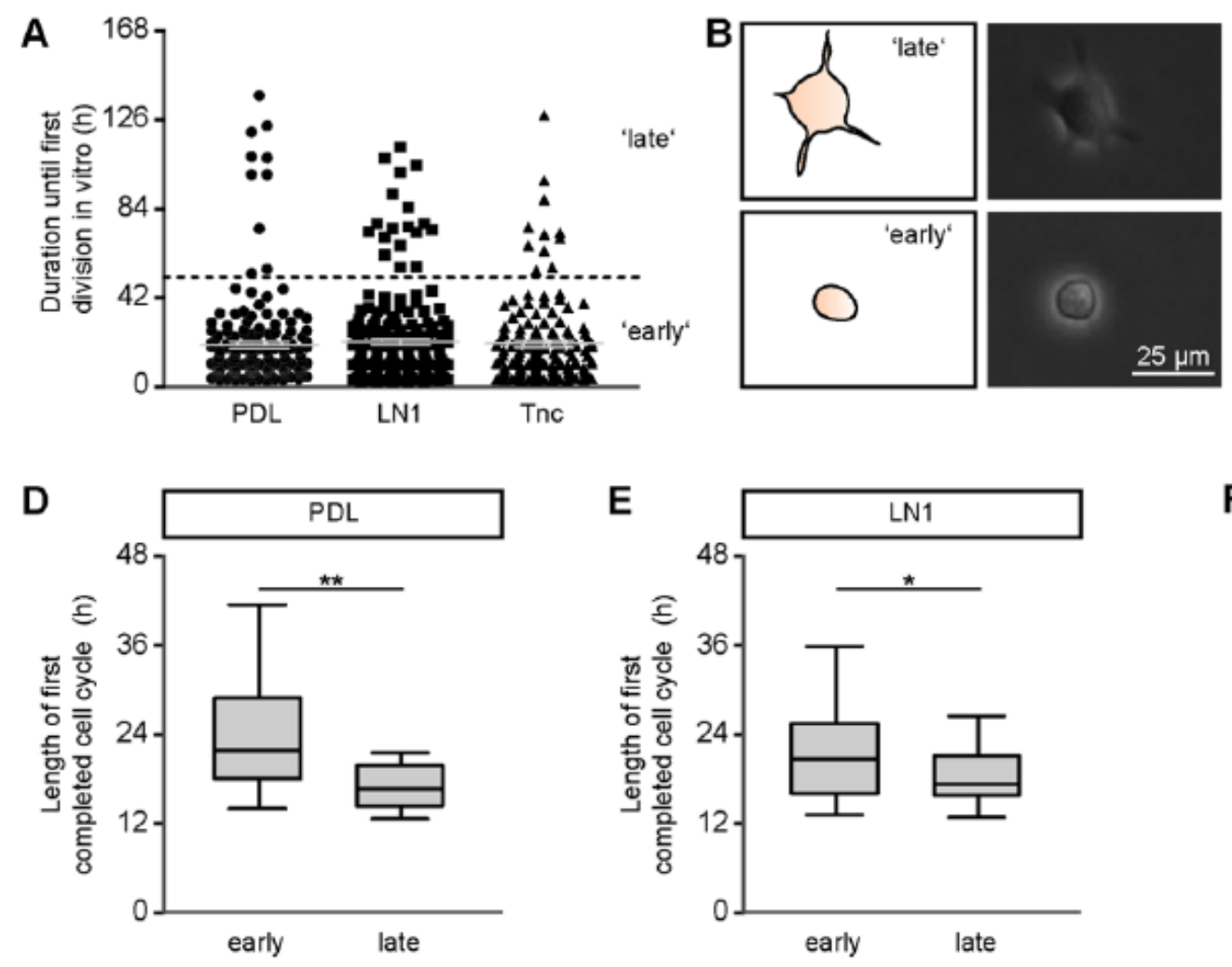
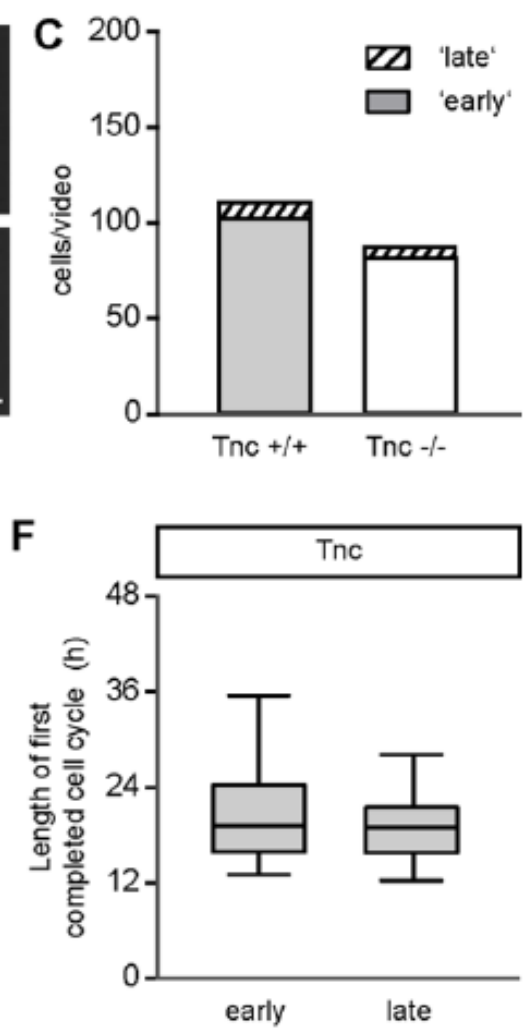

\section{Figure 4}

Late-dividing stem cells are a veritable subpopulation in primary SEZ cultures. (A) The graph presents the duration until the first division in vitro for every mother cell of the wildtype dataset, separately plotted for the three substrate conditions PDL $(n=171, N=5)$, LN1 $(n=185, N=5)$ and Tnc $(n=141, N=5)$. Gray lines represent mean \pm s.e.m. The scatter of data points revealed a gap around 50 hours of documentation. This boundary was used to define a threshold (black dotted line) that separates a subset of $10 \%$ of the dividing cells from the majority located underneath the threshold. (B) A morphological examination of both populations presented as scheme (left) and in phase contrast images (right) indicates that the 'late'labelled aNSPClate subpopulation possesses larger cell bodies with outgrowing branches (top) in comparison to the 'early'-labelled mitotic aNSPCearly cells with a phase-bright round cell body (bottom). 
Scale bar: $25 \mu \mathrm{m}$. (C) Bar chart illustrating the diverging fractions of early- and late-dividing cells in wildtype and Tnc-deficient cultures. Independently of the genotype, late-dividing aNSPCslate represented a minority of less than $10 \%$ of the dividing cells in the SEZ cultures. (D-F) Comparing the length of the first completed cell cycle between early- and late-dividing wildtype cells indicated a significant decrease in the cell cycle of late-dividing cells on PDL (D) and LN1 (E), but not on Tnc (F). The Mann-Whitney U test was used for statistical analysis ( $\left.{ }^{*} p<0.05, * * p<0.01\right)$.
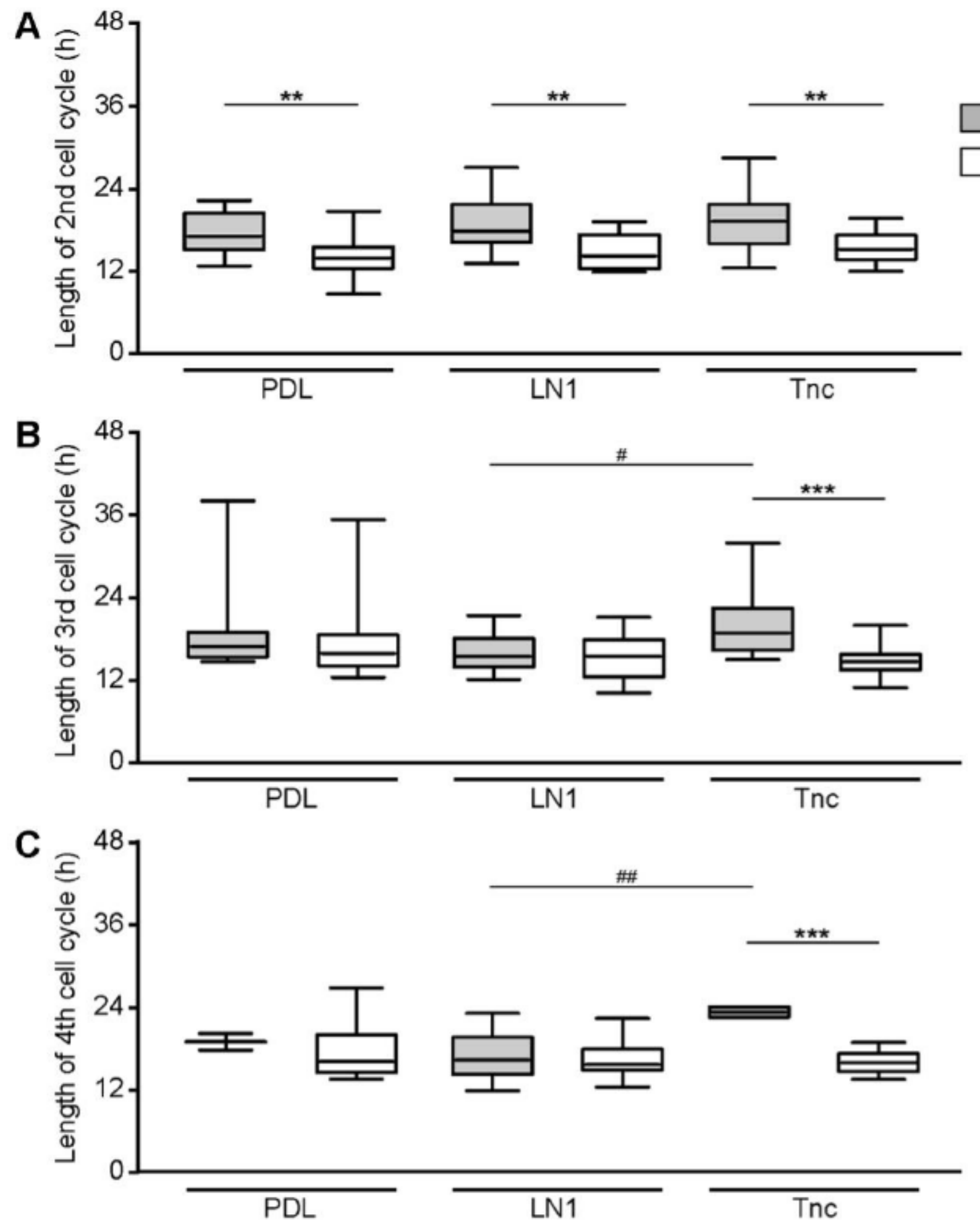

Figure 5 
Cell cycle lengths of the wildtype and Tnc-knockout subset of slow-dividing aNSPClate. (A-C) Cell cycle lengths of late-dividing wildtype (gray) and knockout aNSPClate (white) are presented in box-whiskerplots with 5-95\% percentiles from the $2 n d(A)$, 3rd (B) and 4th (C) generation (N=5, n=2-37). (A) In the 2nd generation, the cell cycle length was reduced in Tnc-deficient cells in the control, on LN1 and on Tnc substrates compared to their wildtype counterpart. (B) Exposure to Tnc as substrate led to a significantly elongated cell cycle in the 3rd generation of wildtype cells compared to the LN1 substrate. (C) This effect was maintained up to the 4th generation, which underscored the opposite effect of the Tnc substrate on the slow-dividing subset of aNSPClate in comparison to the majority of the proliferative population. In Tnc-deficient aNSPClate, we could not detect differences between the different substrate conditions in any generation. Extensive information concerning the number of analyzed cells is presented in supplementary table S3. Statistical evaluation was conducted using the Kruskal-Wallis test with Dunn's multiple comparison for comparing substrates $\left({ }^{*} p<0.05\right.$, $\left.{ }^{*} p<0.01\right)$. The Mann-Whitney $U$ tests were performed to analyze differences between wildtype and knockout data ( $\star \star x<0.01, \star \star \star p<0.001)$. 

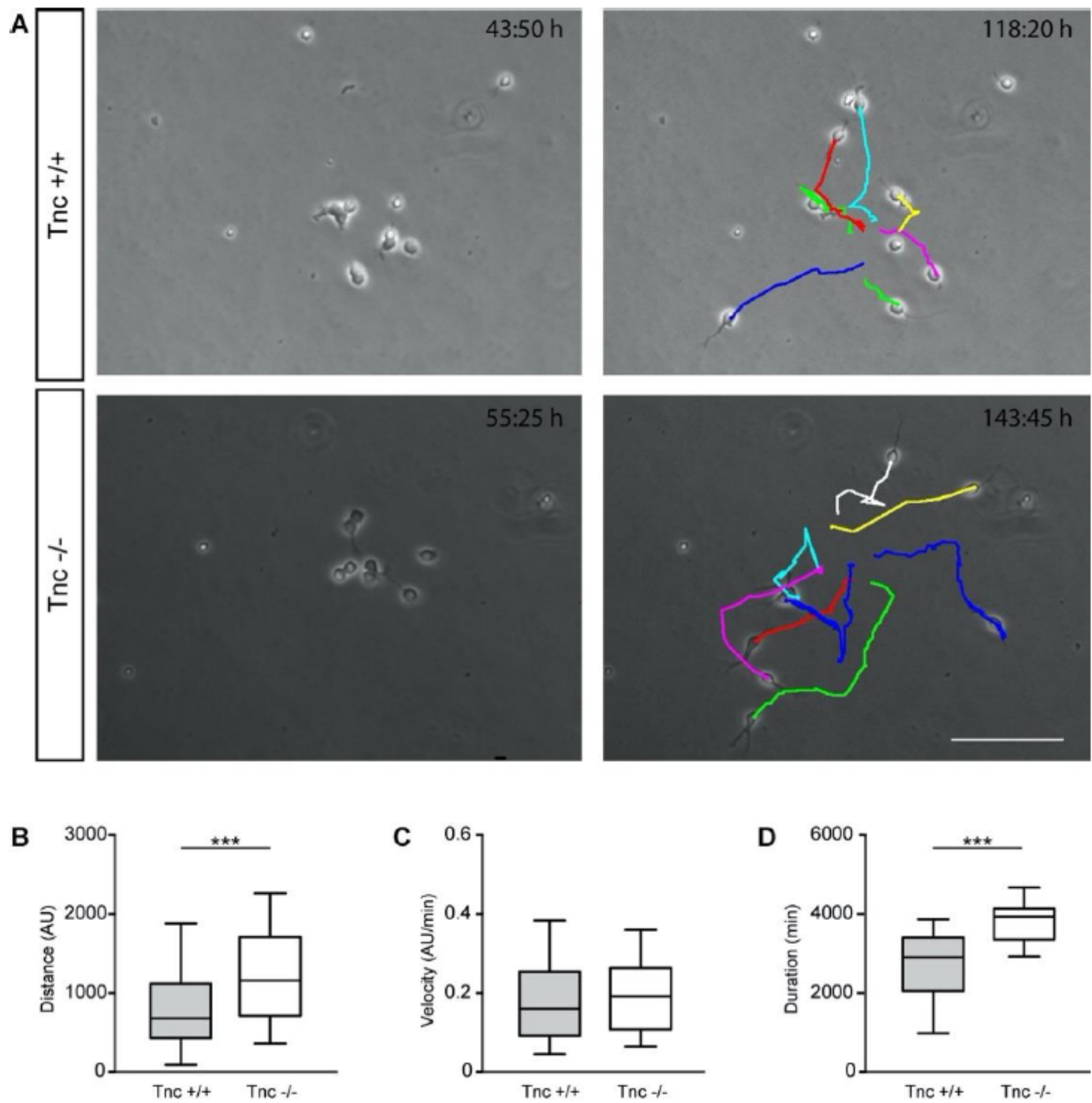

\section{Figure 6}

Neuroblast migration is increased in Tnc-deficient cultures. (A) Phase contrast images of wildtype and Tnc-knockout aNSPCs on PDL substrate illustrate the generation of neuroblasts during time-lapse video microscopy (left) and the tracks of their migration (right), evaluated with the manual tracking plugin of FIJI software. Please note the individual time stamp within each micrograph. Scale bar: $100 \mu \mathrm{m}$. (B) Bar chart presenting the covered distance in arbitrary units (AU). Tnc-deficient cells cover a significantly longer distance compared to the control $(N=3, n=32)$. (C) Analysis of the velocity in AU per minute reveal that the observed changes in distance are not caused by a higher velocity of Tnc-knockout cells, as the 
speed range is equal in both groups $(\mathrm{N}=3, \mathrm{n}=32)$. (D) Evaluation of the temporal sequence ( $\mathrm{min})$ shows a significant increase of the duration of migratory phases for Tnc-deficient compared to wildtype neuroblasts. Duration is measured from initiation of migration to the moment the neuroblast arrests and remains immobile $(N=3, n=32)$. Data are presented as mean \pm s.e.m. The unpaired two-tailed t-test was used for statistical analysis (** $p<0.001)$.

A
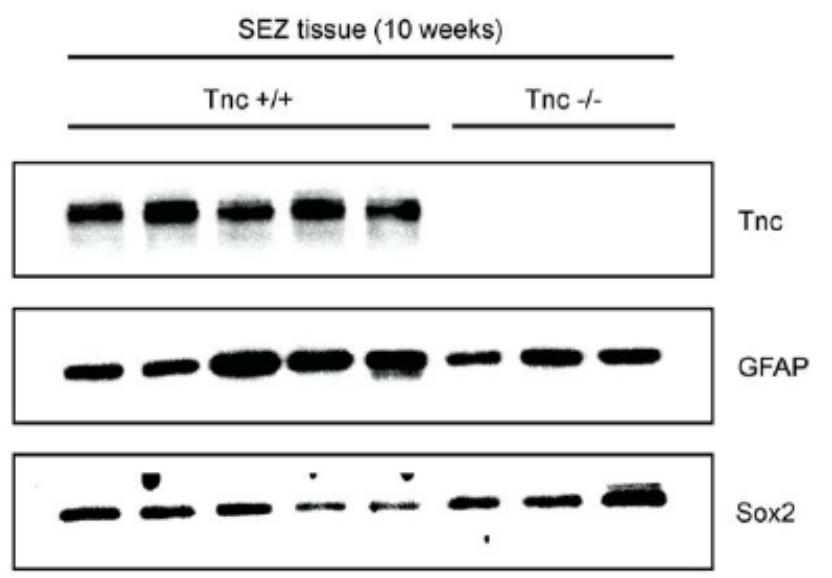

Sox2
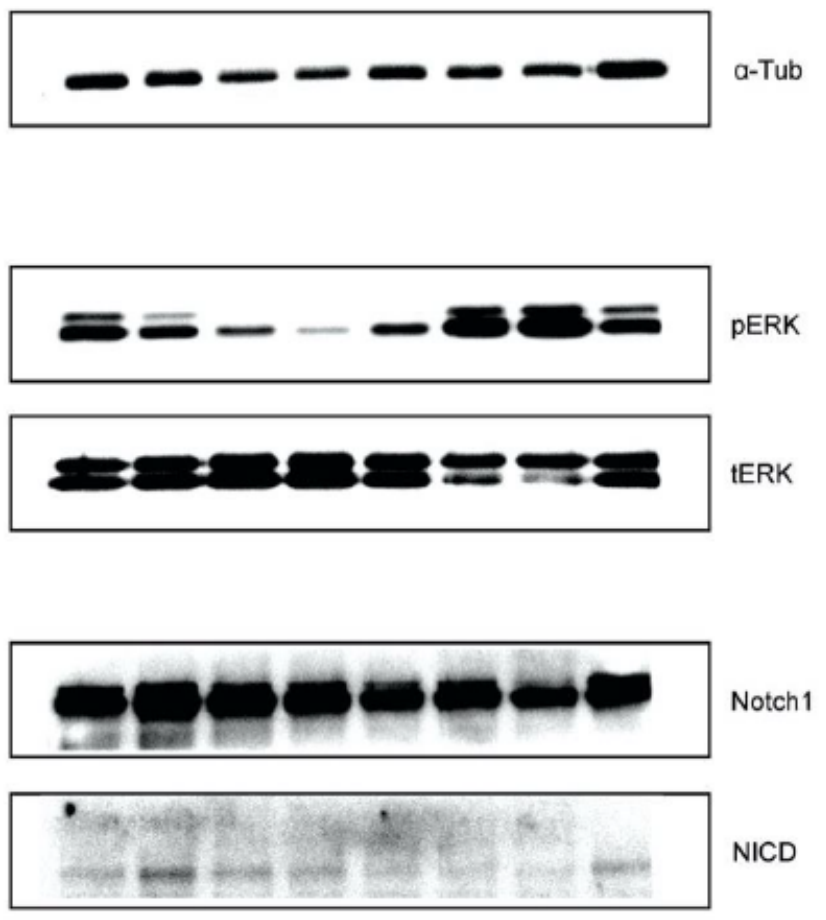

F
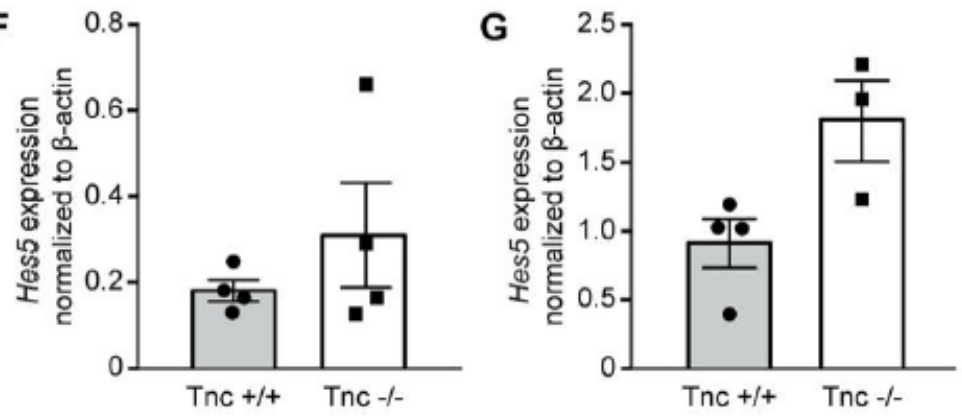
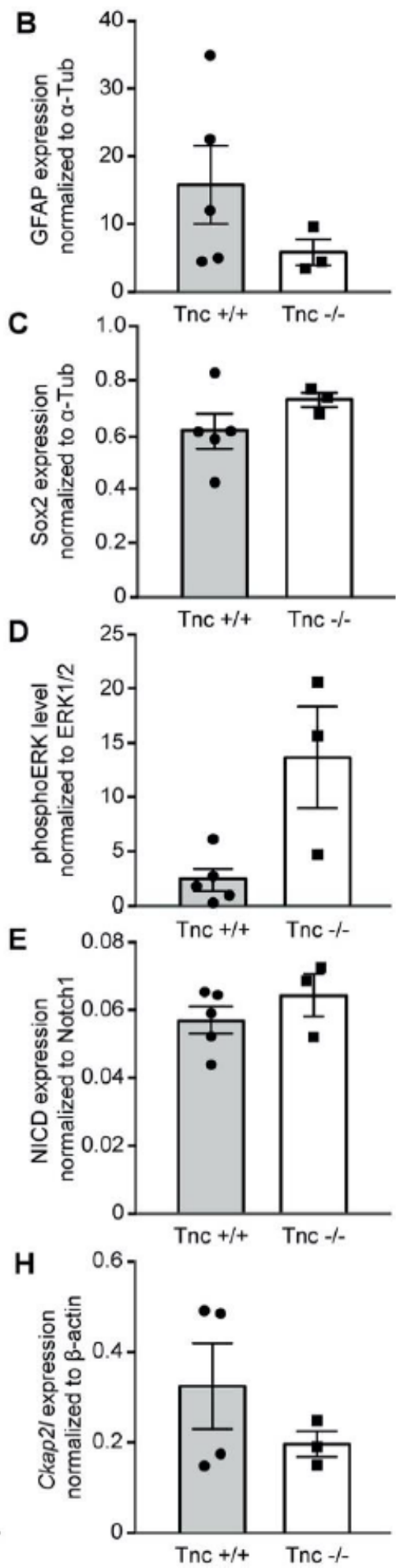

Figure 7 
Analyses of gene expression in the lateral ventricular wall tissue from 10-week old mice. (A) Investigation of protein levels by Western blot technique. The analysis comprised five wildtype samples $(N=5)$ and three Tnc-deficient samples ( $\mathrm{N}=3)$, as confirmed by pk anti-Tnc staining. The levels of GFAP and Sox 2 in each sample were normalized to a-tubulin. (B) Quantification of GFAP signals demonstrated strongly decreased levels in Tnc-deficient SEZ tissue of animals. (C) Examination of Sox2 signals showed a slight increase of Sox2 expression levels in the knockout tissue. (D-E) Analysis of signaling pathways in the lateral ventricular wall tissue from 10-week old mice. Quantification of pERK signals demonstrated strongly increased phosphorylation levels in Tnc-deficient SEZ tissue (D). Notch intracellular domain (NICD) expression in each sample was related to the corresponding Notch1 level (wildtype $N=5$, knockout $\mathrm{N}=3$ ). The ratio reflected an unaltered Notch pathway in knockout tissue (E). ( $F$ ) Analysis of mRNA levels by RT-PCR suggested an implication of the Tnc-knockout in the Notch pathway activation and cell cycle progression. Tnc-deficient mice at 10 weeks of age showed an increased expression level of the target gene Hes5 in tissue isolated from the lateral ventricular wall $(N=4)$. $(G)$ mRNA samples isolated from E15 neurospheres after 7 days in vitro also displayed increased Hes 5 expression in Tnc-deficient cells $(\mathrm{N}=4)$. (H) E15 neurospheres after 7 days of cultivation in suspension were tested for differences in the expression level of the cytoskeleton associated protein 2-like (Ckap2l) that encodes for a mitotic spindle protein. Ckap2l expression in Tnc-deficient neurospheres was reduced compared to wildtype neurospheres $(\mathrm{N}=4)$. Data show mean \pm s.e.m.

\section{Supplementary Files}

This is a list of supplementary files associated with this preprint. Click to download.

- 210629SupplementSchaberg.docx

- M1WTPDLkompr.avi

- M2KOPDLkompravi

- M3KOLN1kompr.avi

- M4KOTnckompr.avi 